\begin{abstract}
AN ANALYSIS OF SPECIFIC LIFE SATISFACTION DOMAINS AND DISORDERED EATING AMONG COLLEGE STUDENTS
\end{abstract}

by Molly Matthews

This thesis examines the relationship between life satisfaction (e.g., family, friends, etc.) and eating behaviors/weight perceptions of 723 college students. Participants completed the survey and data were analyzed using correlations and logistic and multinomial regressions (genders analyzed separately). Satisfaction with Self and Physical Appearance were the strongest correlates with eating variables (-.528 to .369$)$. Worrying about weight (-.528 to -.104$)$, selfdescribed weight (-.407 to -.129$)$, and binging (.110 to .186) were significantly correlated with all LS domains $(p<.05)$. Practitioners should focus on Physical Appearance and Self as entry points for interventions. Researchers should explore the utilization of social norming techniques for shifting the concept of the "ideal" body to one that is more appropriate. Future research should examine the hypothesis that social support may mediate the relationship between life dissatisfaction and poor weight perceptions and dieting behaviors because of previous literature and the results from this study combined. 


\title{
AN ANALYSIS OF SPECIFIC LIFE SATISFACTION DOMAINS AND DISORDERED EATING AMONG COLLEGE STUDENTS
}

\author{
A Thesis \\ Submitted to the \\ Faculty of Miami University \\ in partial fulfillment for the degree of \\ Master of Science \\ Department of Kinesiology and Health \\ by \\ Molly Ruth Hendricks Matthews \\ Miami University \\ Oxford, Ohio \\ 2009
}

Advisor

Dr. Keith Zullig

Reader

Dr. Rose Marie Ward

Reader

Dr. Thelma Horn 


\section{TABLE OF CONTENTS}

CHAPTER I - INTRODUCTION

Disordered Eating Overview

Disordered Eating vs. Eating Disorders

CHAPTER II - REVIEW OF LITERATURE

4

Correlates of Disordered Eating in General and By Gender

Life Satisfaction

Relationship between Disordered Eating and Life Satisfaction

Overview of Current Study

CHAPTER III - METHODS

Overview of Study Design

Research Questions

Participants

Data Collection Procedures

Instrumentation

Brief Multidimensional Student Life Satisfaction Scale-College Version (BMSLSS-C)

Body Weight \& Dietary Behavior Variables

Data Analyses

CHAPTER IV- RESULTS

Descriptive Statistics

Preliminary Analyses

Main Analyses

CHAPTER V- DISCUSSION

Summary of Findings

Limitations

Implications

LIST OF REFERENCES 


\section{LIST OF TABLES}

Page

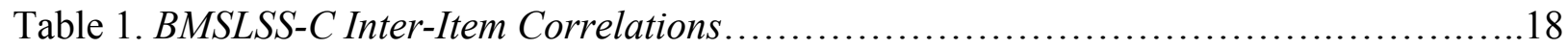

Table 2. Descriptive Data for All Study Participants..........................................24

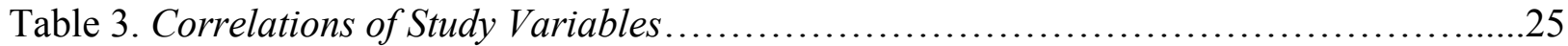

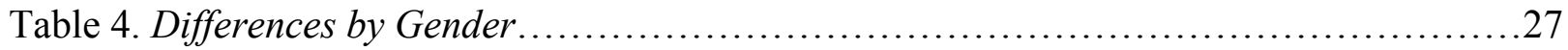




\section{LIST OF FIGURE}

Page

Figure 1: Range of Eating Behaviors................................................. 


\section{CHAPTER I}

\section{INTRODUCTION}

Adolescents are at a particularly high risk for the development of eating problems (including college students; e.g., Budd, 2007). Studies indicate that $0.5 \%$ of all adolescents suffer from anorexia and $3 \%$ from bulimia (Vaughan \& Fouts, 2003). According to the fourth edition of the Diagnostic and Statistical Manual (DSM-IV-TR; American Psychiatric Association, 2000), the definition of anorexia includes a refusal to maintain normal body weight, a fear of gaining weight, as well as either restrictive dieting accompanied by a misuse of laxatives, diuretics, or enemas, and a binge-purge or purging method. The DSM-IV-TR diagnostic criteria for bulimia, like anorexia, is characterized by a preoccupation with one's weight; however, bulimia differs from anorexia in that it is characterized by a binging episode and is frequently followed by purging via vomiting or a misuse of laxatives or enemas.

These numbers for anorexia and bulimia do not include persons with subclinical eating problems which may be much higher (Shisslak, Crago, \& Estes, 1995). Disordered eating includes different types of eating behaviors ranging in severity. Disordered eating may include such things as eating too quickly, not eating enough, eating irregularly, even food restriction, bulimia, and anorexia nervosa (e.g., Grieve, Wann, Henson, \& Ford, 2006; Milligan \& Pritchard, 2006). These maladaptive behaviors are more prominent among those with clinical eating disorders than in those with disordered eating (Bunnell, Shenker, Nussbaum, Jacobson, \& Coolper, 1990; Mitz \& Betz, 1988; Vohs, Heatherton, \& Herrin, 2001).

Further, researchers have noted that studies have primarily focused on clinical eating disorders. While disordered eating behaviors do not always qualify as clinical eating disorders, these behaviors still have ramifications. In order to better understand the differences between eating disorders and disordered eating, some researchers have placed eating behaviors on a continuum from normal eating patterns to clinical eating disorders, with disordered eating somewhere in between (Polivy \& Herman, 1987; see Figure 1.).

Figure 1.

Range of Eating Behaviors.

Normal Eating

Subclinical Disordered Eating

Clinical Eating Disorder

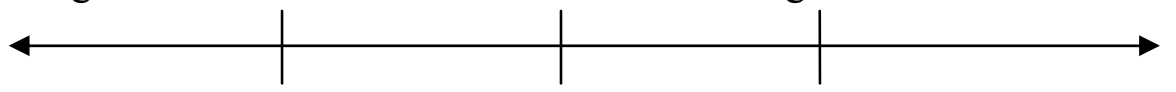


Because disordered eating does not qualify as a clinical eating disorder, and disordered eating behaviors are much more difficult to detect, it is believed that disordered eating behaviors occur at much higher rates, to the extent that some researchers estimate these behaviors occur at least twice the number of times of clinical eating disorders (Shisslak et al., 1995).

Subclinical disordered eating characteristics include: a history of eating disorder symptoms (Clinton \& Glant, 1992); participation in myriad abnormal behaviors, such as those previously mentioned (Jaffe \& Singer, 1989); onset at ages older than clinical eating disorders; and, somatic complaints yet little distorted body image (Shisslak et al., 1995). Further, persons suffering from disordered eating possess certain poor mental characteristics. Body dissatisfaction (e.g., Cooley \& Toray, 2001; Laliberte, Newton, McCabe, \& Mills, 2007), poor self-esteem (e.g., Boyes, Flecher, \& Latner, 2007; Laliberte et al., 2007), drive for thinness (e.g., Santonastaso, Friederici, \& Favaro, 1999), stress (e.g., Thome \& Espelage, 2004), inaccurate body perception/poor body image (e.g., Wharton, Adams, \& Hampl, 2008), perfectionism, obsessivecompulsion/need for control, and depressive symptoms (e.g., Boyes et al., 2007) are significantly related to disordered eating.

Because disordered eating encompasses many different eating behaviors and to date there is not a consistent definition of disordered eating (Breen, Desilva, \& Espelage, 2005), it would be well to define here what the definition of disordered eating is for the purposes of the current study. For this study disordered eating may be defined as abnormal behaviors to control weight including binge eating, exercising/vomiting/laxative use/dietary supplements to lose weight, taking dietary supplements to gain weight, or a preoccupation with body shape and/or weight which lie mostly under the "subclinical disordered eating" category across the continuum in Figure 1.

Given that some abnormal eating behaviors do not fit neatly into a clinical eating disorder category, disordered eating has begun to be studied with more frequency. For example, Rosenzweig and Spruill (1987) longitudinally examined the incidence and severity of bulimiclike behaviors in 159 women who were first-year college students in 1965. Women were asked to complete questionnaires as college freshmen, and were then asked to complete the same questionnaire regarding dieting behaviors 20 years later in 1985. Results of this study revealed that though vomiting frequency remained stable throughout the years, more women engaged in laxative, diuretic, and diet pill use for weight control than they did during college (Rosenzweig 
$\&$ Spruill, 1987). Further, more women were binge eating 20 years later than they were as college freshman (Rosenzweig \& Spruill, 1987).

Though both men and women may present disordered eating behaviors, they do differ in terms of which correlates are more prominent. Both genders afflicted with disordered eating may present the following: increased perceived stress, depressive symptoms, perfectionism, anxiety, and need for control. Drive for thinness has been found mostly in women; however, in studies including homosexual men, those with disordered eating behaviors were found to have similar levels of drive for thinness as heterosexual women. Body dissatisfaction is another correlate that is found in both women and men, but the difference lies in the causes of dissatisfaction. For instance, most women desire to lose weight whereas most men desire to gain muscle mass. Finally, a subjective component of quality of life (life satisfaction) has also been determined to be correlated with the presence of disordered eating behaviors.

Life satisfaction has been defined as one's subjective perception about the "quality of one's own existence" (p. 23, Post, Van Dijk, Van Asbeck, \& Schrijvers, 1998) and is important to study in relation to disordered eating because of the whole host of correlates that are associated with disordered eating play a role in one's sense of life satisfaction. There is a relative dearth of literature exploring life satisfaction and disordered eating behavior, but studies have explored disordered eating among young adolescents, (Esch \& Zullig, 2008), older adolescents (e.g., Valios, Zullig, Huebner, \& Drane, 2003), college populations (e.g., Zullig, Pun, \& Huebner, 2007), and adult populations (Greeno, Jackson, Williams, \& Fortmann, 1998). In each of these populations, those who reported elevated levels of disordered eating also reported reduced overall satisfaction with life.

While previous studies have examined life satisfaction globally as it relates to disordered eating, at present, no studies have examined the specific domains of life satisfaction and their possible correlations to disordered eating behaviors. Further, although notable exceptions exist, most studies concerning disordered eating address only women. Therefore, the purpose of the current study will be to examine which, if any, of the specific domains of life satisfaction are more strongly related to disordered eating behaviors in college students, and to examine whether or not the link between the specific life satisfaction domains and disordered eating differ across gender. If certain life satisfaction domains are found to exert more influence on disordered eating behavior, more focused gender-specific interventions could be developed in response. 


\section{CHAPTER II}

\section{REVIEW OF LITERATURE-CORRELATES OF DISORDERED EATING}

Disordered eating practices in adolescents have been linked with the deterioration of physical and mental health (Swallen, Reither, Haas, \& Meier, 2005). Some examples of physical and mental health include the number of illness symptoms experienced within a year, selfesteem, and depression (Swallen et al., 2005). While non-clinical disordered eating and mortality risk have not been specifically examined, clinical eating disorders and mortality risk have been examined and it has been found that those with clinical eating disorders are at a higher risk for both mortality and suicide (Berkman, Lohr, \& Bulik, 2007). Because of this increased risk for mortality among those with eating disorders, it is highly conceivable that those with sub-clinical disordered eating behaviors may also be at a higher risk for mortality and suicide.

This section reviews the correlates of disordered eating in several notable areas. Gender differences are also noted because studies examining disordered have found unequivocally that females are more afflicted with disordered eating than are males (e.g., Kashubeck-West, Mintz, \& Weigold, 2005; Tata, Fox, \& Cooper, 2001; Thompson \& Sherman, 1999; Woodside et al., 2001). Further, of those afflicted with disordered eating, women are generally more concerned with weight loss whereas men are generally more concerned with weight gain (e.g., Thompson \& Sherman, 1999). Thompson and Sherman (1999) included several studies which examined the effects of gender on eating disorders and found that gender plays a significant role in the development of eating disorders, such that women are more frequently afflicted by eating disorders than men.

Gender differences may be due to elevated societal pressures placed on women to be thin (e.g., Battle \& Brownell, 1996; Bissell \& Zhou, 2004; Cohen \& Petrie, 2005; Demarest \& Allen, 2000; Grieve, Wann, Henson, \& Ford, 2006; Harrison \& Cantor, 1997; Polivy \& Herman, 1987; Tylka \& Hill, 2004), which may result in women generally having higher body dissatisfaction than men (Demarest \& Allen, 2000; Giles, Helme, \& Kraemar, 2007; Mintz \& Betz, 1986). Because some differences between men and women have been noted among the correlates of disordered eating, the following review details relevant gender differences when warranted. Body Dissatisfaction

Body dissatisfaction is defined as how satisfied one is with his or her body (Gleaves, Williamson, Eberenz, Sebastian, \& Barker, 1995) and has been found to be a key component of 
disordered eating (Brannan \& Petrie, 2008; Cooley \& Toray, 2001; Laliberte, Newton, McCabe, \& Mills, 2007; Shutz \& Paxton, 2007). In fact, in a recent study conducted by Brannan and Petrie (2008), body dissatisfaction accounted for $16 \%$ to $26 \%$ of the variance between disordered eating symptoms. Inaccurate perception of one's own body is also correlated with disordered eating symptoms (Wharton et al., 2008). Satisfaction with one's body can even be decreased with minimal exposure to idealized body images. For example, Cahill and Mussap (2007) conducted a study to examine the short-term ramifications of viewing idealized bodies (e.g., thin female models, muscular male models) and found that both women and men reported lower body satisfaction after viewing the idealized images when compared with their pre-exposure scores. This result may explain the higher incidence of disordered eating among those who are most exposed to the media.

Media exposure, even in small doses, affects body satisfaction in both males and females. For example, Cahill and Mussap (2007) exposed both male and female participants to idealized body images and gathered all participants' body satisfaction pre- and post-exposure. Participants' post-exposure body satisfaction scores were obtained immediately following the exposure to the idealized body images. Results indicate that women's increased body dissatisfaction was linked with drive for thinness, whereas men's increased body dissatisfaction was linked with muscle development (Cahill \& Mussap, 2007). Other researchers (e.g., Anderson \& Bulik, 2004; Kashubeck-West et al., 2005) have found similar results. Kasubeck-West et al. (2005) found women in their sample desired the loss of approximately 9 pounds, whereas the men in the sample desired the gain of almost 5 pounds.

An interesting theory posited by Fredrickson and Roberts (1997) suggests possible reasons for an increase in body dissatisfaction: Objectification Theory. Objectification Theory states that women who internalize others' (e.g., family members, friends, significant others) perspectives of themselves as their own continuously engage in body monitoring, possibly manifesting itself in the form of an eating disorder (Fredrickson \& Roberts, 1997). Adolescents view attractiveness in terms of thinness (Brouwers, 1988), especially, females (Shomaker \& Furman, 2007). Given their age, college students are at risk for the development of an eating disorder because of the pressures from their peers to be more attractive (e.g., thin for women and muscular for men). 
Body dissatisfaction has been determined to be a factor in disordered eating among both women and men. The difference is in which areas the genders are affected. For example, a study conducted by Conley and Boardman (2007) found that among normal weight women, an overestimation of weight by $5 \%$ or more significantly predicted the presence of one or more disordered eating behaviors when all other risk factors are controlled. This study indicates that when women perceive themselves to weigh more than they actually do, they are significantly more likely to be afflicted with disordered eating. Men on the other hand, who reported being dissatisfied with their musculature (muscle dissatisfaction) demonstrated significantly higher scores of disordered eating on the Eating Disorders Inventory than those men who did not express a dissatisfaction in their musculature ("Muscle Dissatisfaction in Young Men," 2004; Ricciardeli \& McCabe, 2004).

Even when men desire to lose weight, their body dissatisfaction is reported as lower than women who desire to lose weight. A study by Ricciardeli and McCabe (2004) examined both men and women who desired to lose weight and their body dissatisfaction scores. These results support the statement that while both men and women experience body dissatisfaction, women tend to have more body dissatisfaction (Kashubeck-West et al., 2005).

\section{Poor Self-Esteem}

High body dissatisfaction has also been linked with low self-esteem (e.g., Boyes, Flecher, \& Latner, 2007; Button, Loan, Davies, \& Sonuga-Barke, 1997; Granillo, Jones-Rodriguex, \& Carvajal, 2005; Laliberte et al., 2007; Tylka \& Subich, 1999). A longitudinal study revealed that an increase in body dissatisfaction was predicted by low self-esteem (Gilbert \& Meyer, 2005). The results from this study indicate that low self-esteem, coupled with high body dissatisfaction, can result in disordered eating behaviors and/or depression (Gilbert \& Meyer, 2005). Self-esteem is generally comorbid with body dissatisfaction, such that if one has high body dissatisfaction then their self-esteem will be low. Therefore, self-esteem has been determined to be a correlate of disordered eating such that poor self-esteem contributes to the existence of disordered eating symptoms (Vohs, Bardone, Joiner, Abramson, \& Heatherton, 1999), though accompanying high body dissatisfaction.

Shea and Pritchard (2007) were interested in examining whether or not low self-esteem was a primary predictor of disordered eating. These researchers found that though very influential, poor self-esteem was a secondary predictor of disordered eating rather than a primary 
predictor (Shea \& Pritchard, 2007) when gender was not taken into account. However, evidence suggests that this relation between poor self-esteem and disordered eating differs between males and females. Both of the studies conducted by Santos, Richards, and Bleckley (2007) and Muris, Meesters, van de Blom, and Mayer (2005) found that self-esteem was not a primary predictor of disordered eating in males but it was a primary predictor in females. Reasons for this result were not discussed; however, it is possible, given the notion of Objectification Theory that females look more externally for self-esteem than do males. Another study which examined only adolescent males found no relationship between body dissatisfaction and poor self-esteem (Furnham \& Calnan, 1998).

\section{Drive for Thinness}

Drive for thinness (DT) is generally defined as an extreme fear of gaining weight and an over concern for dieting (Gravener, Haedt, Heatherton, \& Keel, 2008). DT has been determined to be a primary predictor of disordered eating (e.g., Christiano \& Mizes, 1997; Levitt, 2003; Santonastaso, Friederici, \& Favaro, 1999). DT is often triggered when a discrepancy between ideal and actual weight is present (Sands, 2000). Sands (2000) examined DT as a three component (perceptual, affective/attitudinal, and behavioral) construct and found that these components significantly predicted disordered eating behaviors. Of these three components, the affective/attitudinal construct had the strongest prediction. These results indicate that DT is significantly related to disordered eating.

Drive for thinness, according to the research, seems to be most correlated with females suffering from disordered eating behaviors, rather than males (e.g., Yelland \& Tiggeman, 2003). However, homosexual men's drive for thinness scores are similar to heterosexual women's drive for thinness scores among those with disordered eating (Yelland \& Tiggemann, 2003). This finding points strongly to the idea that drive for thinness is correlated with the perception of what is viewed as most attractive to those with disordered eating symptomology or what one believes others view as most attractive.

\section{Perceived Stress}

Perceived stress (e.g., how stressed one believes themselves to be) is associated with disordered eating, likely due to ineffective coping mechanisms. Ball and Lee's (2000) review of literature provides support that a relationship is present between perceived stress and disordered eating. Striegel-Moore, Silberstein, Frensch, and Rodin (1989) were interested in college 
students' level of perceived stress and presence of disordered eating symptoms upon entry into their first year of college and again at the conclusion of their first year. The results were that high perceived stress was significantly associated with a worsening of disordered eating behaviors over the course of their first year. Additionally, one-fourth of the participants (including both males and females) who were stressed from entering college placed themselves on a diet for the first time during their freshman year (Striegel-Moore et al., 1989).

These results seem to contradict Rosensweig and Spruill's (1987) study discussed in chapter one. Possible reasons for this difference may be that the first-year college women in Rosensweig and Spruill's (1987) study were in their first year of college in 1965, whereas the first-year college women in Striegel-Moore et al.,'s (1989) study were in their first year of college in 1989. Media exposure and the surge of extremely thin models may have lead to this difference. For example, a study looked at the trends for ideal feminine beauty from the years 1959 to 1999 and found that body size drastically reduced during the 1980s and 1990s (Sypeck, Gray, \& Aherns, 2004). Additionally, a marked increase in the number of pictures displaying the entire bodies of the models was also noted from the 1960s to the 1990s (Sypeck et al., 2004). Finally, these researchers note that this trend in the modeling industry for more thin models corresponds with an increase in disordered eating behaviors among women in America (Sypeck et al., 2004). As further evidence of media playing a role is Rosensweig and Spruill's (1987) finding that the women in their study were engaging in more weight regulating behaviors 20 years after 1965 than they were in their first year of college.

An interesting study conducted recently suggests that perceived stress precedes disordered eating behaviors, leading to the idea that perceived stress may actually be a risk factor for the development of disordered eating. Striegel-Moore, Dohm, Kraemer, Schreiber, Taylor, and Daniels (2007) included women who did and did not have a history of eating disordered behaviors and found that those women who had a history of eating disordered behaviors experienced an increased amount of perceived stress prior to the onset of their disordered eating behaviors.

Perceived stress has been found to be a correlate of disordered eating (Jenkins, Rew, \& Sternglanz, 2005) and particularly binge eating (Striegel-Moore et al., 1989; Wolff, Crosby, Roberts, \& Wittrock, 2000), regardless of gender. Of concern, this relationship between stress 
and unhealthy eating practices can even be detected among children as early as the fourth, fifth, and sixth grades (Jenkins et al., 2005).

Depressive Symptoms

Depressive symptoms (Boyes et al., 2007) are significantly related to disordered eating. A study examining depression and disordered eating in a sample of adolescents revealed that these were comorbid for both male and female participants and that there were no gender differences (Santos et al., 2007). Measelle, Stice, and Hogansen (2006) longitudinally examined depressive symptoms, eating pathology, antisocial behavior, and substance abuse in females annually for 5 years. At the beginning of the study, participants' ages ranged from 12 to 15 years old. Results from this study reveal that as depressive symptoms increase, disordered eating behaviors increase as well (Measelle et al., 2006).

Although women overall are more afflicted with disordered eating than men, those persons who develop disordered eating behaviors are more likely to experience depressive symptoms, regardless of their gender (e.g., Boyes et al., 2007; Measelle et al., 2006; O’Dea \& Abraham, 1999; Santos et al., 2007).

\section{Perfectionism}

Perfectionism, a component of obsessive-compulsive disorder (OCD), has been demonstrated to be significantly correlated with disordered eating behaviors, which may help explain why disordered eating is often found to be comorbid with OCD in women college students (Humphreys, Clopton, \& Reich, 2007; Macedo, Soares, Azevedo, Gomes, Pereira, Maia, \& Pato, 2007) as well as in men (Macedo et al., 2007).

Few studies have examined both the male and female genders, but those that have examined both genders found that perfectionism is a correlate of disordered eating in both men and women (e.g., Humphreys, Clopton, \& Reich, 2007; Macedo, Soares, Azevedo, Gomes, Pereira, Maia, \& Pato, 2007).

\section{Anxiety}

Anxiety has been found to be a contributing factor to disordered eating symptomology (e.g., Steiner \& Lock, 1998). Researchers even point to the idea that those persons who experience perceived anxiety earlier than others are most at risk for the reoccurrence of disordered eating behaviors (Hautala, Junnila, Helenius, Vaananen, Liuksila, Raiha et al., 2008). 
Conversely, those participants who did not have perceived anxiety only temporarily experienced eating problems (Hautala et al., 2008).

Anxiety has been determined to be a contributing factor to the development of disordered eating behaviors. When examining both males and females with disordered eating, more similarities are present than differences. Both males and females who suffer from disordered eating symptomology also have higher rates of anxiety (Hautala et al., 2008). Need for Control

Need for control has been determined to be a correlate of disordered eating behaviors (Budd, 2007). Researchers believe that disordered eating behaviors occur in part as a method to control one's life when they experience a lack of control in many other aspects of their life. Thus, people may turn to disordered eating behaviors, such as controlling their food intake, as a means to establish some control over their own life (Polivy \& Herman, 2002).

It appears that both males and females suffering from disordered eating behaviors display an increased need for control than those who do not engage in disordered eating. Thus, little difference is apparent between the two genders in terms of need for control as a correlate of disordered eating (Polivy \& Herman, 2002).

In summary, the research examined in this section indicates that there are several psychological characteristics common in adolescents and young adults afflicted with disordered eating behaviors. Specifically, it appears that such psychological characteristics as body dissatisfaction, depression, drive for thinness, and low self-esteem may be correlated with higher tendencies for adolescents and young adults to develop and exhibit disordered eating behaviors. However, it also appears that the psychological characteristics of disordered eating may somewhat vary by gender. For example, gender differences were noted for psychological characteristics. In particular, women with disordered eating were more likely to posses drive for thinness and perfectionism characteristics whereas men were more likely to posses wants to gain bulk muscle.

An additional psychological characteristic that may be linked to disordered eating behaviors in adolescents and young adults is their level of life satisfaction. Life satisfaction is of particular interest because high life satisfaction has been linked with feelings of the highest quality of interpersonal relationships (e.g., relationships with teachers, parents, classmates, and friends; Suldo \& Huebner, 2006). Both men and women who report higher levels of social 
support report higher levels of happiness and lower levels of stress (Rosenthal, Gensten, \& Shiffman, 1986). In addition, those who have the highest quality of interpersonal relationships, and in turn have the highest life satisfaction, report higher levels of academic, emotional, and social self-efficacy than those who reported low life satisfaction (Suldo \& Huebner, 2006). Life satisfaction has been studied in college students, which is of interest because higher life satisfaction has been associated with feelings of higher levels of academic self-efficacy (Suldo \& Huebner, 2006). The research and theory corresponding to life satisfaction is reviewed in the following sections.

\section{Life Satisfaction}

While there are various definitions (Flece \& Perry, 1995), the quality of life (QOL) can be defined as one's sense of wellbeing. QOL has also been demonstrated to have several domains including: family, self, living environment, friends, and school (Cummins, 1996). In addition, QOL has been defined both objectively and subjectively, where subjectivity is how an individual weights each domain (previously noted) by their own personal feelings of importance for that particular domain. An aspect of the subjective QOL component is life satisfaction.

Life satisfaction can be defined as an assessment of one's perceived quality of life and involves a process of cognition and judgment (Diener, Emmons, Larsen, \& Griffin, 1985) in various life domains such as friends, self, and work. Health status has also been to be influenced by one's perceived life satisfaction. For instance, Palmore and Luikart (1972) state that those who are more satisfied with their life tend to be healthier than those who are less satisfied with their lives. In their study, Palmore and Luikart (1972) participants' self-rated health was a stronger predictor of their life satisfaction than was their physician's rating of their health. Among a large sample of adolescents, Zullig, Valois, Huebner, and Drane (2005) found that those who rated their health lower, or reported having a higher number of poor physical and mental health days also reported reduced levels of life satisfaction. Thus, not only is life satisfaction related to psychological health, but also to physical health. Other research has linked reduced life satisfaction to increased risk for suicide and poor mental health (Hun \& Hyun, 2008; Valois, Zullig, Huebner, \& Drane, 2004).

Disordered Eating and Life Satisfaction

Studies examining life satisfaction and health-related maladaptive behaviors (e.g., suicide, substance use, alcohol misuse) have been a fairly recent phenomenon (Valios, Zullig, 
Huebner, \& Drane, 2004; Zullig, Valios, Huebner, \& Drane, 2001). However, fewer researchers have examined the relation between levels of perceived life satisfaction and the health-related maladaptive behaviors of disorder eating. The next section will review the extant literature among various age groups.

\section{Young Adolescents}

Only one study was located in the literature for young adolescents. This cross-sectional study examining 245 middle school students (Esch \& Zullig, 2008) found that even in persons as young as seventh and eighth grade, a lower life satisfaction score was correlated with females who reported eating less to lose weight. This finding was not present among male participants in the study. However, both female and male participants who reported fasting for 24 or more hours in order to lose weight scored lower levels of life satisfaction when compared with those participants who did not report fasting. Females who reported using diet pills, powders, or liquids in order to lose weight scored significantly lower levels of life satisfaction than females who did not. These findings suggest that there is a relationship between disordered eating and lowered levels of life satisfaction among persons as young as seventh and eighth grade.

\section{Older Adolescents}

Although still relatively small, more research has been conducted with older adolescents to date. Examining clinical eating behaviors, a study conducted by Halvorsen and Heyerdahl (2006) studied 44 females who were hospitalized (under 18 years old). These females were then re-examined when they had reached young adulthood (e.g., over 18 years old), had completed their treatment, and were either placed into the positive outcome group (no eating disorder) or the negative outcome group (still had eating disorder). All of the participants completed the Mini International Neuropsychiatric Interview (MINI), the Yale-Brown Obsessive Compulsive Scale, the Eating Disorder Examination (EDE), and a semistructured interview to assess sexual abuse. Participants in the positive outcome group reported having higher life satisfaction than those participants in the negative outcome group. Further, life satisfaction and eating disorders were highly negatively correlated (Halvorsen \& Heyerdahl, 2006).

Valois, Zullig, Huebner, and Drane (2003) studied life satisfaction and disordered eating behaviors (e.g., dieting) among a large sample of public high school students $(\mathrm{N}=5,032)$. Results from this study found that in both male and female adolescents reduced life satisfaction was correlated with: perception of being overweight, trying to lose weight, dieting to lose 
weight, vomiting/using laxatives to lose weight, and using diet pills to lose weight. Among male participants, reduced life satisfaction was also correlated with perceptions of being underweight. This finding is not surprising, given the body of research suggesting that males who are dissatisfied with their musculature experience more disordered eating behaviors (e.g., "Muscle Dissatisfaction in Young Men," 2004). These results indicate that a reduced sense of life satisfaction is correlated with inappropriate means of weight reduction among both male and female adolescents. Not only have adolescents' life satisfaction and disordered eating behaviors been studied, but so too has the college population.

\section{College Population}

A qualitative study conducted by Kitsantas, Gilligan, and Kamata (2003) examined the effect of eating disorders on life satisfaction. A total of 56 college women participated and were individually interviewed to examine how they felt about their weight and whether or not they suffered from eating disorders. In addition, the participants completed the Extended Satisfaction with Life Scale (ESWLS), The Eating Disorder Inventory-2 (EDI), and the Positive and Negative Affect Scale (PANAS). Results from this study revealed that those suffering from eating disorders had significantly lower life satisfaction than those who do not suffer from eating disorders (Kistsantas, Gilligan, \& Kamata, 2003).

Watt, Sharp, and Atkins (2002) also examined life satisfaction and disordered eating behaviors in college women. This study consisted of a total of 96 participants recruited from various college courses and they were informed that the study was to investigate body image among college women. Of the 96 participants included in the study, $30 \%$ were categorized as having a preoccupation with dieting and $17 \%$ were categorized as actually engaging in purging behavior (Watt et al., 2002). When examining the results of the personal control measures, the more the participants tended to have self-attributions, the more likely they were to attribute successes to themselves rather than failures, demonstrating that self-attributions are not redundant items of personal control. In addition, self-attributions for failure were more related to a preoccupation with dieting when in conjunction with life satisfaction (Watt et al., 2002). These results indicate that there is a negative correlation between high life satisfaction and disordered eating.

Zullig, Pun, and Huebner (2007) demonstrated that dissatisfaction with life and perceptions of underweight, overweight, somewhat worried about weight, very worried about 
weight, binge eating at least once a month, worrying about binge eating, binge eating for 1 or more years, and having purged at least once to remove food are all related in female participants. In male participants, the researchers found a relation between dissatisfaction with life and perceptions of being underweight or worried about weight (Zullig et al., 2007).

\section{Adult Population}

In addition to determining that life satisfaction is related to disordered eating in young and older adolescent populations as well as college-aged populations, research has also determined that life satisfaction is related to disordered eating in the adult population. Greeno et al. (1998) were interested in examining whether one's higher body mass index (BMI), or one's perceived lack of control over eating, or both, were factors that contributed to life satisfaction levels in 2,132 women and men. These researchers found that in women, a lack of perceived eating control and a higher BMI score were related to a lower life satisfaction score and a lack of control over eating. In men it was found that a lack of perceived control was predictive of lower life satisfaction (Greeno et al., 1998).

\section{Summary of Life Satisfaction and Disordered Eating}

Though life satisfaction has been widely studied in maladaptive behaviors, fewer studies have linked life satisfaction with disordered eating behaviors. The few studies that have been completed in this area (e.g., Esch \& Zullig, 2008; Greeno et al., 1998; Kitsantas et al., 2003; Valois, Zullig, Huebner, \& Drane, 2003; Watt et al., 2002; Zullig et al., 2007) have found that life satisfaction is negatively related to disordered eating in adults, college students, and older and younger adolescents. However, these research studies have not investigated which particular domains of life satisfaction are more strongly related to disordered eating. Domains shown to be important for adolescents include satisfaction with family, friendships, school experience, self, and place of residence (Huebner, 1994). Recently, college students were shown to have additional domains of importance such as satisfaction with romantic relationships and physical appearance (Zullig et al., in press).

Because previous research reviewed in this paper has indicated that the psychological correlates or predictors of disordered eating differ according gender, it may also be important to determine whether the specific domains of life satisfaction are differently related to disordered eating behaviors in male and female college students, as this information could better inform specific interventions addressing quality of life issues and disordered eating among college 
students. Based on the correlates of disordered eating literature, it appears that some domains of life satisfaction may be more influential than others.

For example, given that disordered eating behaviors are correlated with drive for thinness in women and muscle gain for men, as well as self-esteem and body dissatisfaction for both genders, satisfaction with physical appearance may be highly influential among both women and men. In addition, because perfectionism was found to be a correlate in women and need for control was found to be a correlate in both women and men, satisfaction with self may be influential among both women and men. Further, because people with disordered eating behaviors care about what others believe about them (Objectification Theory), satisfaction with friends and satisfaction with family may also be influential domains of life satisfaction. And finally, given the body of previous research noting that life satisfaction is related to disordered eating, it is hypothesized that the global life satisfaction component will be influential.

Thus, the purposes of the current study are to: (a) determine which, if any, of the specific domains of life satisfaction are related to disordered eating behaviors in college students, and to (b) determine whether differences in this relationship between life satisfaction domains and disordered eating behaviors exist differ across gender. Based on the literature concerning correlates of disordered eating, it is hypothesized that the individual domains of life satisfaction that will be most influential will be Satisfaction with Physical Appearance and Satisfaction with Self. Furthermore, based on previous research indicates gender differences in the correlates of disordered eating, it is also expected that the links found in this study between the sub-domains of life satisfaction and college students' disordered eating behaviors will differ as a function of students' gender. 


\section{CHAPTER III \\ RESEARCH METHODS}

\section{Research Questions}

The current study is guided by nine questions. Each of these questions will be explored by gender and be answered with data analysis, and will be discussed in the results section.

1. Which domains of life satisfaction will be predictive of poor weight perceptions/body dissatisfaction among college students?

2. Which domains of life satisfaction will be predictive of worrying about weight issues among college students?

3. Which domains of life satisfaction will be predictive of binge eating behavior among college students?

4. Which domains of life satisfaction will be predictive of exercising to lose weight among college students?

5. Which domains of life satisfaction will be predictive of vomiting or taking laxatives to lose weight among college students?

6. Which domains of life satisfaction will be predictive of taking dietary supplements to lose bulk or weight among college students?

7. Which domains of life satisfaction will be predictive of taking dietary supplements to gain bulk or weight among college students?

8. Which domains of life satisfaction will be predictive of how weight influences feelings about self among college students?

9. Which domains of life satisfaction will be predictive of drive for thinness among college students?

Sample

During February 2007, 1,300 students aged 18 years of age or older were randomly selected from the referent university's e-mail data base to participate in the web-delivered health survey at this mid-western state university. Equal numbers of students were randomly selected from each class using the uniform distribution number generator function in SAS (Cary, N.C.), giving each student an equal probability of being selected for the sample. This function assigns each student a random number resulting in a representative sample of university students. The 
sample data base included student names, current mailing addresses, and current e-mail addresses.

\section{Instrumentation}

The primary purpose of the current study was to assess the health behaviors of college students. This study's purpose is to assess the relationship between the subdomains of life satisfaction and disordered eating behaviors in college males and females. In order to measure these constructs, a set of scales were used. These scales are described in the following sections. The Brief Multidimensional Student Life Satisfaction Scale-College Version (BMSLSS-C). The dependent variables in this study will be the BMSLSS-C. The BMSLSS-C (Zullig et al., in press) is a 8 -item scale developed from the 40-item Multidimensional Students' Life Satisfaction Scale (Huebner, 1994) and includes questions regarding satisfaction with family, friends, living environment, school, self, romantic relationships, physical appearance, and work. The questions on the BMSLSS-C are as follows: 1) "I would describe my satisfaction with my family life as";

2) "I would describe my satisfaction with my physical appearance as"; 3) "I would described my satisfaction with my romantic relationships as"; 4) "I would describe my satisfaction with my friends as"; 5) "I would describe my satisfaction with my school as"; 6) "I would describe my satisfaction with my living environment as"; and, 7) "I would describe my satisfaction with myself as". The BMSLSS-C uses a Likert scale, where the responses lay on a Terrible-Delighted scale which includes: terrible, unhappy, mostly dissatisfied, mixed (about equally satisfied and dissatisfied), mostly satisfied, pleased, and delighted (Andrews \& Withey, 1976). An eighth global life satisfaction item, "I would describe my satisfaction with my overall life as," was also included.

The BMSLSS-C has demonstrated adequate internal consistency (.80) in a college aged population (Zullig et al., in press). Criterion-related validity was determined with the correlation of the BMSLSS-C total score and the Centers for Disease Control and Preventions HealthRelated Quality of Life Scale (CDC, 1994; Hennessy et al., 1994) and a brief loneliness scale (Hughes et al., 2004). Factor analytic procedures determined the construct validity of the BMSLSS-C, while known-groups validity analyses revealed that life satisfaction decreased as problematic alcohol use increased (Zullig et al., in press). 
In this study, BMSLSS-C correlation coefficients are provided in Table 1. Although all items are significantly correlated, their varying strength suggest the potential separate influence each may carry in their ability to predict disordered eating which will be examined.

Table 1.

BMSLSS-C Inter-Item Correlations

\begin{tabular}{|c|c|c|c|c|c|c|c|c|}
\hline & Domain & 1 & 2 & 3 & 4 & 5 & 6 & 7 \\
\hline 1. & Family & 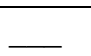 & & & & & & \\
\hline 2. & Friendships & 0.35 & - & & & & & \\
\hline 3. & School & 0.28 & 0.56 & $\ldots$ & & & & \\
\hline 4. & Self & 0.36 & 0.56 & 0.57 & 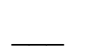 & & & \\
\hline 5. & Environment & 0.20 & 0.42 & 0.49 & 0.38 & 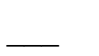 & & \\
\hline 6. & Relationships & 0.26 & 0.28 & 0.23 & 0.40 & $0.11^{*}$ & 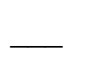 & \\
\hline 7. & Appearance & 0.27 & 0.34 & 0.35 & 0.70 & 0.22 & 0.45 & - \\
\hline 8. & Global & 0.44 & 0.63 & 0.59 & 0.77 & 0.42 & 0.43 & 0.60 \\
\hline
\end{tabular}

All correlations significant at $p<.001$ level unless noted; * $p<.01$

As can be determined from Table 1 above, the correlation between the domains of Satisfaction with Physical Appearance and Satisfaction with Self is $0.70, p<.0001$. Thus, Satisfaction with Physical Appearance and Satisfaction with Self are highly correlated. This being said, it is not surprising that these two domains are the domains which proved to be most predictive of eating behaviors/weight perceptions among both the college females and males who participated in this study.

Body Weight and Dietary Behavior Variables

The dependent variables in the current study were selected body weight and dietary behavior variables from the National College Health Risk Behavior Survey (CDC, 1995) and American College Health Association's National College Health Assessment (NCHA; American College Health Association, 2004). The specific questions are as follows:

1. How do you describe your weight?
a. Very underweight
b. Slightly underweight
c. About the right weight
d. Slightly overweight
e. Very overweight 
2. Within the last 30 days, did you do any of the following? Yes No
a. Binge eat (uncontrolled and excessive eating)
b. Exercise to lose weight
c. Vomit or take laxatives to lose weight
a. Take dietary supplements to lose bulk or weight
b. Take dietary supplements to gain bulk or weight

The Youth Risk Behavior Surveillance System (YRBSS) includes some questions from the National College Health Risk Behavior Survey (NCHRBS), and previous research has shown that the YRBSS displays adequate reliability (Brener, Collins, Kann, Warren, \& Williams, 1995). The NCHA has also shown acceptable inter-item reliability (.4 - .9; American College Health Association, 2004).

The remaining questions were incorporated into the study, but have not been evaluated for their reliability:

1. How worried are you about your weight?
a. Not all worried
b. A little worried
c. Somewhat worried
d. Very worried
e. Extremely worried

2. Is your body shape and weight among the most important things that affect how you feel about yourself?
a Yes, it is the most important aspect of my self-regard
b Yes, it is one of the most important aspects of my self-regard
c No, other aspects are more important

3. Do you need to be very thin in order to feel good about yourself $\underline{\mathrm{OR}}$ do you still feel too fat even though others say you are thin?
a Yes to both questions
b Yes to one of these questions
c No to both questions 
Demographic variables will also be incorporated into the study. These include the following:

1. What year in school are you?
a. First year
b. Sophomore
c. Junior
d. Senior

2. How old are you?
a. 18 years old
b. 19 years old
c. 20 years old
d. 21 or older

3. What is your gender?
a. Male
b. Female

4. Recognizing that these categories are limiting, with which of the following do you best self-identify?
a. White - not Hispanic
b. Black - not Hispanic
c. Hispanic or Latino
d. Asian or Pacific Islander
e. American Indian or Alaskan Native
f. Other

5. Are you a member of a fraternity or sorority?
a. Yes
b. No

6. Which best describes your current living arrangement for college?
a. Residence hall
b. Fraternity house
c. With sorority sisters
d. With fraternity brothers (not in fraternity house) 
e. On-campus apartment

f. Off-campus apartment or house

g. At home with family

h. Other

\section{Data Collection}

Data collection began in February 2007, using web-survey methods (Pealer et al., 2001) and methods approved by the referent university's institutional review board. Selected students $(\mathrm{N}=1,300)$ were sent, via electronic mail and U.S. mail, a solicitation regarding the purpose of the study. Students were also informed that if they chose to participate, they would receive a coupon redeemable at an off-campus café. Seven days after the initial solicitation was sent to each selected participant, a second solicitation was sent via electronic mail with an attached link to the survey. If participants chose to participate, they were directed first to an informed consent statement describing the research procedures and steps taken to protect participants' privacy. Students who chose to participate were then referred to the survey by clicking the referent link. Once each participant submitted their completed survey, any identifying information was separated from their responses and stored in a separate data storage facility, making their responses anonymous. A follow-up e-mail was sent to each participant one week after the survey was originally distributed, followed by one additional U.S. mail and e-mail reminder one week thereafter. A total of 723 usable questionnaires were returned for a $56 \%$ response rate. Statistical Analyses

All data were collected and were entered into a Statistical Package for Social Sciences (SPSS) version 16.0 for windows data file. The relationship between life satisfaction and disordered eating behaviors was examined using correlated procedures, as well as multiple regression. All analyses were run separately for male and female participants because gender differences were noted.

\section{Descriptive Statistics}

First, descriptive statistics were run. The means, standard deviations, and ranges were performed for all variables. In addition, correlations were performed between the BMSLSS-C items (independent variables) and the weight perception and dieting behavior items (dependent variables). The life satisfaction scores from the BMSLSS-C served as the predictor variables because the disordered eating behaviors influenced specific domains of life satisfaction. 


\section{Preliminary Analyses}

The preliminary analyses performed were multivariate analysis of variance (MANOVA) in order to determine if males and females differ in their responses to the BMSLSS-C items and the weight perception and dieting behavior items. In addition, the demographic questions were examined in regards to whether or not differences existed.

\section{Main Analyses}

The main analyses performed were multivariate multiple regression, both logistic and multinomial, and correlation analyses. In this study, the dependent variables were the weight perception and disordered eating scores and the predictor variables were the life satisfaction scores from the BMSLSS-C. These statistics were run separately for males and females because there were gender differences among the eating behavior variables. 


\section{CHAPTER IV}

\section{RESULTS}

The primary aim of this study was to determine whether certain domains of life satisfaction were more influential on selected eating behaviors than were others and, if so, whether this relationship differed as a function of college students' gender. The main study hypothesis was that the relationships between the life satisfaction scores (Self, School, Family, Friends, Romantic Relationships, Physical Appearance, Living Environment, and Overall Life) and the eating behaviors and weight perceptions in college students would differ as a function of gender. Several statistical procedures were performed in SPSS version 17.0 to test the hypotheses. The results are presented in the following sections. First, descriptive statistics are presented, followed by the results for each of the nine research questions previously presented.

\section{Descriptive Statistics}

All four years in school (freshman, sophomore, junior, and senior; $26.7 \%, 21.4 \%, 28.1 \%$, and 23.8\%, respectively) and all four age categories have similar representation $(M=19.89, S D$ $=1.06)$. Most of the sample was Caucasian (91.6\%), female (68.3\%), and not a member of a fraternity or sorority $(68.8 \%)$. These demographics are representative of the composition of the university where data were collected (Miami University, 2006).

Table 2 below provides the mean scores and standard deviations for all study participants on all measures of eating behaviors/weight perceptions and all eight domains of life satisfaction. 
Table 2 .

Descriptive Data for All Study Participants

\begin{tabular}{|c|c|c|c|}
\hline Life Satisfact & & Eating Behaviors/Weig & Perceptions \\
\hline Family Life & & Self-Described Weight & \\
\hline Total & $6.09(1.04) \mathrm{n}=577$ & Total & $3.23(.628) \mathrm{n}=522$ \\
\hline Friendships & & Worried About Weight & \\
\hline Total & $5.89(1.05) \mathrm{n}=572$ & Total & $2.44(1.07) \mathrm{n}=522$ \\
\hline School Exper & & Binge Eat & \\
\hline Total & $5.29(1.22) \mathrm{n}=575$ & Percent 'Yes' & $14.0 \%$ \\
\hline Self & & Exercise to Lose Weigh & \\
\hline Total & $5.49(1.19) \mathrm{n}=576$ & Percent 'Yes' & $61.3 \%$ \\
\hline Living Place & & Vomit/Laxatives to Los & Weight \\
\hline Total & $5.23(1.32) \mathrm{n}=576$ & Percent 'Yes' & $3.9 \%$ \\
\hline Romantic Re & & Supplements to Lose W & ght \\
\hline Total & $4.95(1.66) n=574$ & Percent 'Yes' & $6.0 \%$ \\
\hline Physical App & & Supplements to Gain B & /Weight \\
\hline Total & $4.95(1.24) \mathrm{n}=570$ & Percent 'Yes' & $4.7 \%$ \\
\hline Overall Life & & Importance of Body Sh & \\
\hline Total & $5.71(1.01) \mathrm{n}=570$ & Total & $2.47(.572) \mathrm{n}=514$ \\
\hline & & Need to be Thin/Feel T & Fat \\
\hline & & Total & $2.47(.686) n=508$ \\
\hline
\end{tabular}

* Mean (Standard deviation)

**Response options for the LS items were as follows: $1=$ terrible; $2=$ unhappy; $3=$ mostly dissatisfied; 4=mixed (about equally satisfied and dissatisfied); $5=$ mostly satisfied; $6=$ pleased; $7=$ delighted

Upon examination of Table 2, it is apparent that the sample reported the highest levels of Satisfaction with Family. The lowest levels of satisfaction reported among the sample were Satisfaction with Romantic Relationships and Satisfaction with Physical Appearance. In addition, some variation among the life satisfaction domains exists with the most variability among the domain of Romantic Relationships. On the other hand, there appears to be little variability among the eating behaviors/weight perception variables, with the exception of the variable of worrying about one's weight. 


\section{Preliminary Analyses}

For preliminary analyses, correlations were performed between the specific life satisfaction variables and the weight perception/dieting behavior variables in order to determine whether or not the life satisfaction domains and the eating behavior/weight perception variables were related to each other. Results from these analyses indicated that Satisfaction with Physical Appearance had the strongest correlations with the eating behaviors/weight perception variables ( $r=-.52$ to .36 ) followed by Satisfaction with Self ( $r=-.38$ to .33$)$, Satisfaction with Overall Life ( $r=-.25$ to .21$)$ and Satisfaction with Romantic Relationships ( $r=-.17$ to .13$)$. Worrying about weight ( $r=-.53$ to -.10$)$, self-described weight ( $r=-.41$ to -.13$)$, and binge eating ( $r=.11$ to.19) were also significantly correlated with all eight domains of life satisfaction $(p<.05)$. The specific correlations are denoted in Table 3 below.

Table 3.

Correlations of Study Variables

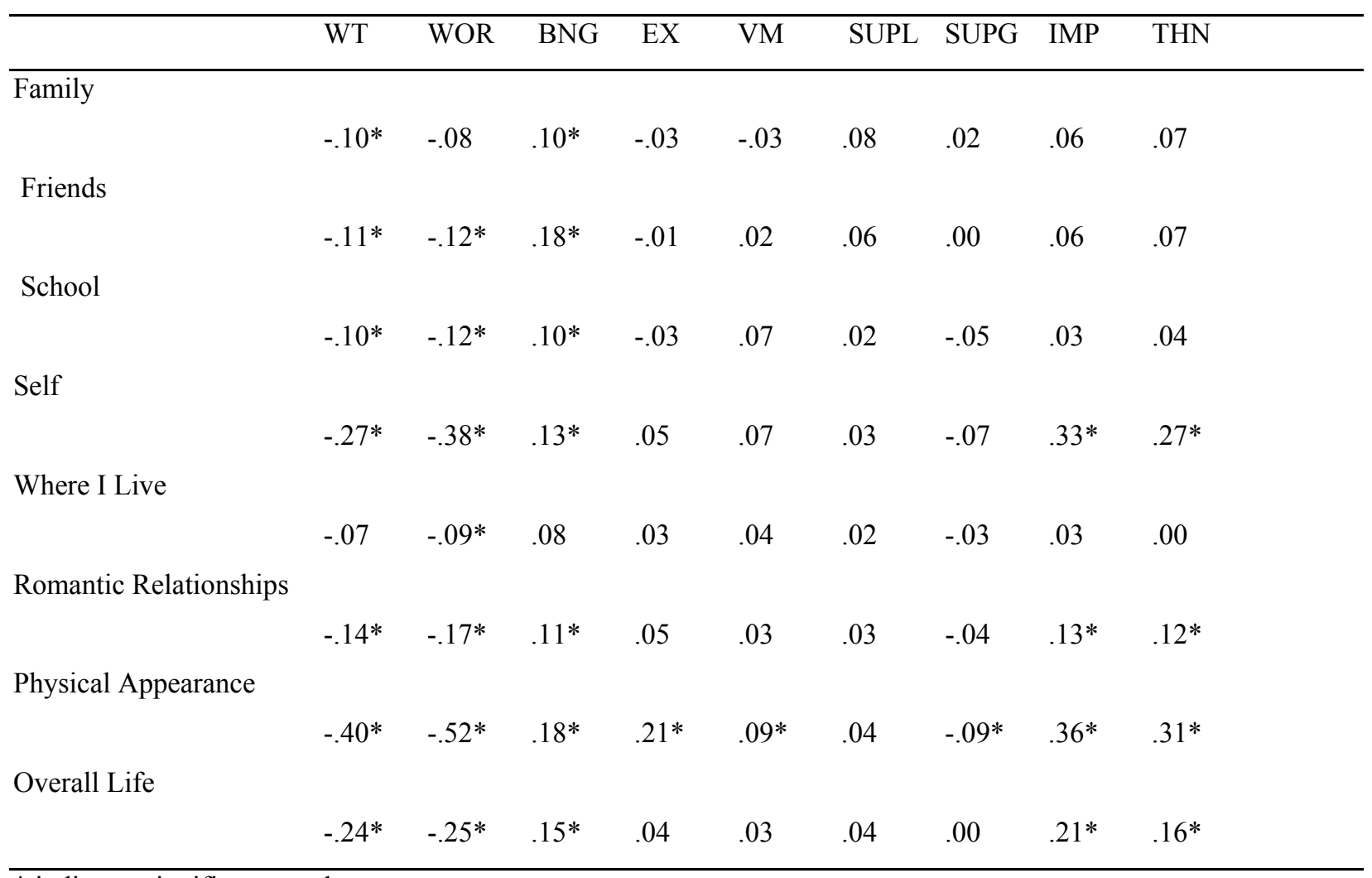

* indicates significant $p$-value

** WT $=$ Self-described weight; WOR $=$ Worried about weight; BNG = Binge eat; EX = Exercise to lose weight; $\mathrm{VM}=$ Vomit or take laxatives to lose weight; SUPL = Dietary supplements to lose weight; SUPG = Dietary supplements to gain weight; IMP = Importance of body weight and shape and how that affects how I feel about myself; THN = I need to be thin to feel good about myself OR I feel too fat even though others say I'm thin 
Preliminary analyses were conducted in order to determine whether males and females differ in their responses to the BMSLSS-C items and the weight perception and dieting behavior items. The life satisfaction scores as measured by the BMSLSS-C and scores of the weight perception/dieting behaviors served as the dependent variables and the independent variable was gender. Using multivariate analysis of variance (MANOVA), males and females responses to the BMSLSS-C items were compared. A second MANOVA was conducted in order to determine males and females responses on the continuous weight perception and dieting behavior items. Lastly, Chi Squares were conducted in order to compare males and females responses on the dichotomous weight perception and dieting behavior items (binge eat, exercise, vomit/take laxatives to lose weight, supplements to lose weight, and supplements to gain weight; Table 4).

MANOVA results indicate that there was a significant difference between males and females among the life satisfaction domains in the sample, Wilks' $\Lambda=.02, p<.001$, partial $\eta^{2}=$ .04. MANOVA results indicate that there was a significant difference between males and females among the continuous eating behavior/weight perception variables, Wilks' $\Lambda=.02, p$ $<.001$, partial $\eta^{2}=.16$. When Chi Squares were computed with the dichotomous eating behavior/weight perception variables, it was evident that there were differences between males and females for each eating behavior except for binge eating and supplements to lose bulk or weight (see Table 4). 
Table 4.

Differences by Gender

\begin{tabular}{|c|c|c|c|c|c|}
\hline \multirow[b]{3}{*}{ Life Satisfaction } & \multicolumn{5}{|c|}{ Wilk's $\Lambda=.96, p<.001$, partial $\eta^{2}=.04$} \\
\hline & Males & Females & & \multirow[b]{2}{*}{$p$} & \multirow[b]{2}{*}{ Cohen's $d$} \\
\hline & $M(S D)$ & $M(S D)$ & $t$ & & \\
\hline Family Life & $6.06(1.08)$ & $6.10(1.02)$ & -.43 & .66 & -0.04 \\
\hline Friendships & $5.89(1.10)$ & $5.88(1.03)$ & .08 & .94 & 0.01 \\
\hline School Experience & $5.27(1.29)$ & $5.29(1.19)$ & -.17 & .87 & -0.02 \\
\hline Myself & $5.68(1.23)$ & $5.41(1.17)$ & 2.48 & $.01 *$ & 0.15 \\
\hline Living Place & $5.26(1.42)$ & $5.22(1.28)$ & .32 & .75 & 0.03 \\
\hline Romantic Relationships & $4.94(1.70)$ & $4.95(1.65)$ & -.06 & .95 & -0.01 \\
\hline Physical Appearance & $5.26(1.21)$ & $4.82(1.23)$ & 3.85 & $<.001 *$ & 0.43 \\
\hline Overall Life & $5.77(1.04)$ & $5.69(0.99)$ & .90 & .37 & 0.08 \\
\hline \multicolumn{6}{|c|}{ Wilk's $\Lambda=.84, p<.001$, partial $\eta^{2}=.16$} \\
\hline Continuous Eating & Males & Females & & & \\
\hline Behaviors/Weight Perceptions & $M(S D)$ & $M(S D)$ & $t$ & $p$ & Cohen's d \\
\hline Describe Weight & $3.13(0.71)$ & $3.26(0.59)$ & -2.15 & $.03 *$ & -0.20 \\
\hline Worried About Weight & $1.87(0.91)$ & $2.67(1.04)$ & -8.18 & $<.001 *$ & -0.82 \\
\hline $\begin{array}{l}\text { Dichotomous Eating } \\
\text { Behaviors/Weight Perceptions }\end{array}$ & $\begin{array}{l}\text { Males } \\
\text { \% 'Yes' }\end{array}$ & $\begin{array}{l}\text { Females } \\
\% \text { 'Yes' }\end{array}$ & Pearson $\chi^{2}$ & $d \boldsymbol{f}$ & $p$ \\
\hline Binge Eat & $13 \%$ & $17.6 \%$ & 1.05 & 1 & 0.31 \\
\hline Exercise to Lose Weight & $38.5 \%$ & $70.5 \%$ & 45.45 & 1 & $<.001 *$ \\
\hline Vomit/Take Laxatives to Lose Weight & $0.7 \%$ & $5.2 \%$ & 5.77 & 1 & $.02 *$ \\
\hline Supplements to Lose Weight & $5.0 \%$ & $6.5 \%$ & 0.59 & 1 & .44 \\
\hline Supplements to Gain Weight & $14.8 \%$ & $1.4 \%$ & 31.63 & 1 & $<.001 *$ \\
\hline $\begin{array}{l}\text { Categorical Eating } \\
\text { Behaviors/Weight Perceptions }\end{array}$ & $\begin{array}{l}\text { Males } \\
\% \text { 'No' }\end{array}$ & $\begin{array}{c}\text { Females \% } \\
\text { 'No' }\end{array}$ & Pearson $\chi^{2}$ & $d \boldsymbol{f}$ & $p$ \\
\hline Importance of Body Shape & $72.1 \%$ & $42.8 \%$ & 6.55 & 1 & $.01 *$ \\
\hline I Need to be Thin/I Feel Too Fat & $46.4 \%$ & $86.6 \%$ & 45.45 & 1 & $<.001 *$ \\
\hline
\end{tabular}

*indicates significant $p$ value

$* * N=570, d f=484$ if not indicated

Upon examining Table 4, it may be seen that differences between males and females in the sample were present for Satisfaction with Self. Almost all of the eating behavior/weight perception variables were statistically different between males and females in the study except for binge eat and supplements to lose weight. When examining Table 4, generally the trend 
among the domains of life satisfaction is that the males in the study report higher levels of satisfaction than do the females. Similarly, males generally report less poor eating behaviors/weight perceptions than do females in the current study; however, males do report using dietary supplements to gain bulk or weight significantly more than do females.

Results from this indicate that males and females differed in their responses to the domains of Satisfaction with Self and Satisfaction with Physical Appearance. In regards to the weight perception and dieting behavior items, males and females differed in their responses to describe your weight, worried about your weight, exercise to lose weight, vomit or take laxatives to lose weight, take dietary supplements to gain bulk or weight, importance of body shape and weight that affect how I feel about myself, and I need to be thin to feel good about myself OR I feel too fat even though others say I'm thin. In Table 4, using the guidelines for interpreting effect sizes from Cohen (1988), a small effect is .2, a medium effect is .5, and a large effect is .8 . The effect sizes for the domains of Satisfaction with Self and Satisfaction with Physical Appearance.

Next, a series of linear regressions were performed between the individual weight perception/dieting behavior variables and all of the individual domains of life satisfaction in order to explore the research questions. The life satisfaction scores were the independent variables and the weight perception/dieting behavior scores were the dependent variables for each analysis. To assess for gender differences, male and female participants were analyzed separately. All life satisfaction domains were entered at once even though only Satisfaction with Self and Satisfaction with Physical Appearance appeared to be significantly different between males and females in the sample. The linear regression which was run was a stepwise because there may be some multicollinearity between Satisfaction with Self and Satisfaction with Physical Appearance.

\section{Main Study Analysis}

Hypothesis One: Which domains of life satisfaction will be predictive of self described weight among college students?

The eight domains of life satisfaction served as the predictor variables while the dependent variable was describe your weight. For the male participants, the overall ANOVA was reported as $F(2,143)=12.38, S S=10.70, p<.001$ and only Satisfaction with Physical Appearance $(\beta=-.47, t=-4.87, p<.001)$ and Satisfaction with Romantic Relationships $(\beta=.19$, 
$t=2.03, p=.04)$ were significant predictors of self-described body weight. For the female participants, the overall ANOVA was reported as $F(2,365)=72.07, S S=20.92, p<.001$ and only Satisfaction with Physical Appearance was a significant predictor $(\beta=-.41, t=-8.49, p<$ $.001)$. Thus, it appears that for both males and females that the domain of satisfaction with physical appearance was the only life satisfaction domain related to self described weight. Hypothesis Two: Which domains of life satisfaction will be predictive of worrying about weight issues among college students?

The eight domains of life satisfaction served as the predictor variables while the dependent variable was worried about your weight. For the male participants, the overall ANOVA was reported as $F(1,144)=51.67, S S=31.30, p<.001$ and only Satisfaction with Physical Appearance was a significant predictor of worrying about weight $(\beta=-.51, t=-7.19, p$ $<.001)$. For the female participants, the overall ANOVA was reported as $F(1,365)=119.51, S S$ $=97.62, p<.001)$ and only Satisfaction with Physical Appearance was a significant predictor $(\beta$ $=-.50, t=-10.93, p<.001)$. Thus, it appears that for both males and females that only satisfaction with physical appearance was related to worrying about weight issues. Hypothesis Three: Which domains of life satisfaction will be predictive of binge eating behavior among college students?

The eight domains of life satisfaction served as the predictor variables while the dependent variable was binge eat. Because the variable binge eat is dichotomous, a binary logistic regression was performed. All variables were entered into the equations at once using an enter method. For the males, the model that resulted was non-significant, $\chi^{2}(144)=10.23, p=$ .25 , Cox and Snell $\mathrm{R}^{2}=.07$. For the females, the model that resulted was significant, $\chi^{2}$ (364) $=$ $17.78, p=.02$, Cox and Snell $\mathrm{R}^{2}=.05$. With respect to the males, only Satisfaction with Friends $(\mathrm{OR}=2.24)$ was a significant predictor. For the females, only the constant $(\mathrm{OR}=.10)$ was a significant predictor. With respect to classifications, $0 \%$ of the males in the yes category and $100 \%$ of the no category were correctly classified. Overall, $89.6 \%$ of the males were correctly classified. A total of $0 \%$ of the females in the yes category and $99.4 \%$ of the no category were correctly classified. Overall, $84.3 \%$ of the females were correctly classified. 
Hypothesis Four: Which domains of life satisfaction will be most predictive of exercising to lose weight among college students?

The eight domains of life satisfaction served as the predictor variables while the dependent variable was exercise to lose weight. Because the variable exercise to lose weight is dichotomous, a binary logistic regression was performed. All variables were entered into the equations at once using an enter method. For the males, the model that resulted was significant, $\chi^{2}(144)=17.46, p=.02$, Cox and Snell $\mathrm{R}^{2}=.11$. For the females, the model that resulted was significant, $\chi^{2}(361)=23.49, p<.01$, Cox and Snell $\mathrm{R}^{2}=.06$. With respect to the males, Satisfaction with Physical Appearance $(\mathrm{OR}=1.62)$ and Satisfaction with Self $(\mathrm{OR}=.42)$ were significant predictors. For the females, Satisfaction with Physical Appearance $(\mathrm{OR}=1.78)$ was a significant predictor. With respect to classifications, $39.3 \%$ of the males in the yes category and $78.4 \%$ of the no category were correctly classified. Overall, $63.2 \%$ of the males were correctly classified. A total of $98.1 \%$ of the females in the yes category and $8.3 \%$ of the no category were correctly classified. Overall, $71.5 \%$ of the females were correctly classified.

Hypothesis Five: Which domains of life satisfaction will be most predictive of vomiting or taking laxatives to lose weight among college students?

The eight domains of life satisfaction served as the predictor variables while the dependent variable was vomit or take laxatives to lose weight. Because the variable vomit or take laxatives to lose weight is dichotomous, a binary logistic regression was performed. All variables were entered into the equations at once using an enter method. For the males, the model that resulted was non-significant, $\chi^{2}(144)=1.26, p=.99$, Cox and Snell $\mathrm{R}^{2}=.02$. For the females, the model that resulted was non-significant, $\chi^{2}(361)=7.51, p=.48$, Cox and Snell $\mathrm{R}^{2}=.02$. None of the domains of life satisfaction were significant for males or females. With respect to classifications, $0 \%$ of the males in the yes category and $100 \%$ of the no category were correctly classified. Overall, $99.3 \%$ of the males were correctly classified. A total of $0 \%$ of the females in the yes category and $100 \%$ of the no category were correctly classified. Overall, $94.7 \%$ of the females were correctly classified.

Hypothesis Six: Which domains of life satisfaction will be most predictive of taking dietary supplements to lose bulk or weight among college students?

The eight domains of life satisfaction served as the predictor variables while the dependent variable was take dietary supplements to lose bulk or weight. Because the variable 
take dietary supplements to lose weight is dichotomous, a binary logistic regression was performed. All variables were entered into the equations at once using an enter method. For the males, the model that resulted was non-significant, $\chi^{2}(144)=6.10, p=.64$, Cox and Snell $\mathrm{R}^{2}=.04$. For the females, the model that resulted was non-significant, $\chi^{2}(365)=7.57, p=.48$, Cox and Snell $\mathrm{R}^{2}=.02$. None of the domains of life satisfaction were significant for the males. Only Satisfaction with Family $(\mathrm{OR}=1.48)$ was a significant for females. With respect to classifications, $0 \%$ of the males in the yes category and $100 \%$ of the no category were correctly classified. Overall, $95.1 \%$ of the males were correctly classified. A total of $0 \%$ of the females in the yes category and $100 \%$ of the no category were correctly classified. Overall, $93.4 \%$ of the females were correctly classified.

Hypothesis Seven: Which domains of life satisfaction will be most predictive of taking dietary supplements to gain bulk or weight among college students?

The eight domains of life satisfaction served as the predictor variables while the dependent variable was taking dietary supplements to gain bulk or weight. Because the variable take dietary supplements to gain weight is dichotomous, a binary logistic regression was performed. All variables were entered into the equations at once using an enter method. For the males, the model that resulted was non-significant, $\chi^{2}(144)=7.21, p=.51$, Cox and Snell $\mathrm{R}^{2}=.05$. For the females, the model that resulted was non-significant, $\chi^{2}(364)=7.32, p=.50$, Cox and Snell $\mathrm{R}^{2}=.02$. None of the domains of life satisfaction were significant for males or females. With respect to classifications, $0 \%$ of the males in the yes category and $100 \%$ of the no category were correctly classified. Overall, $86.8 \%$ of the males were correctly classified. A total of $0 \%$ of the females in the yes category and $99.4 \%$ of the no category were correctly classified. Overall, $98.6 \%$ of the females were correctly classified.

Hypothesis Eight: Which domains of life satisfaction will be most predictive of how weight influences feelings about self among college students?

The eight domains of life satisfaction served as the predictor variables while the dependent variable was importance of body shape and weight that affect how I feel about myself. Because the variable of body shape and weight that affect how I feel about myself is categorical, a multinomial multiple regression was performed. The no, other aspects are more important category was selected to be the point of contrast for the other two categories of yes, it is the most important aspect of my self-regard and yes, it is one of the most important aspects of my self- 
regard. Only the domains of self, romantic relationships, physical appearance and overall life were placed into the equations because those were the variables which were significantly related to the variable importance of body shape and weight that affect how I feel about myself. All variables were entered into the equations at once. For the males, a non-significant Deviance estimate was produced, $\chi^{2}(146)=140.39, p=.95$. The model that resulted was $\chi^{2}(146)=16.06$, $p=.04$, Cox and Snell pseudo $\mathrm{R}^{2}=.10$. For the females, a non-significant Deviance estimate was produced, $\chi^{2}(365)=264.86, p=.93$. The model that resulted was $\chi^{2}(365)=66.09, p>.001$, Cox and Snell pseudo $\mathrm{R}^{2}=.17$.

When predicting the male membership of the yes, it is the most important aspect of my self-regard category, none of the domains of life satisfaction were significant predictors. When predicting the male membership of the yes, it is one of the most important aspects of my selfregard category, none of the domains of life satisfaction were significant predictors. When predicting the female membership of the yes, it is the most important aspect of my self-regard category, Satisfaction with $\operatorname{Self}(\mathrm{OR}=.38)$ was a significant predictor. When predicting the female membership of the yes, it is one of the most important aspects of my self-regard category, Satisfaction with Self $(\mathrm{OR}=.52)$, Satisfaction with Physical Appearance $(\mathrm{OR}=.69)$, and Satisfaction with Overall Life $(\mathrm{OR}=1.46)$ were significant predictors.

With respect to classifications, $25.0 \%$ of the males in the yes, it is the most important aspect of my self-regard category, $0 \%$ of the yes, it is one of the most important aspects of my self-regard, and $97.1 \%$ of the no, other aspects are more important were correctly classified. Overall, $70.5 \%$ of the males were correctly classified. A total of $0 \%$ of the females in the yes, it is the most important aspect of my self-regard category, $67.9 \%$ of the yes, it is one of the most important aspects of my self-regard, and $68.6 \%$ of the no, other aspects are more important were correctly classified. Overall, $65.2 \%$ of the females were correctly classified.

Hypothesis Nine: Which domains of life satisfaction will be most predictive of drive for thinness among college students?

The eight domains of life satisfaction served as the predictor variables while the dependent variable was importance of body shape and weight that affect how I feel about myself. Because the variable importance of body shape and weight that affect how I feel about myself is categorical, a multinomial multiple regression was performed. The no to both of these questions category was selected to be the point of contrast for the other two categories of yes to one of 
these questions and yes to both of these questions. All variables were entered into the equations at once. For the males, a non-significant Deviance estimate was produced, $\chi^{2}(228)=106.05, p=$ 99. The model that resulted was $\chi^{2}(228)=16.01, p=.45$, Cox and Snell pseudo $\mathrm{R}^{2}=.11$. For the females, a non-significant Deviance estimate was produced, $\chi^{2}(228)=694.15, p=.22$. The model that resulted was $\chi^{2}(491)=52.56, p>.001$, Cox and Snell pseudo $\mathrm{R}^{2}=.14$.

When predicting the male membership of the yes to both questions category, none of the domains of life satisfaction were significant predictors. When predicting the male membership of the yes to one of these questions category, none of the domains of life satisfaction were significant predictors. When predicting the female membership of the yes to both questions category, only Satisfaction with $\operatorname{Self}(\mathrm{OR}=.51)$ was a significant predictor. When predicting the female membership of the yes to one of these questions category, only Satisfaction with Physical Appearance $(\mathrm{OR}=.65)$ was a significant predictor.

With respect to classifications, $33.3 \%$ of the males in the yes to both questions category, $6.2 \%$ of the yes to one of these questions, and $100 \%$ of the no to both of these questions were correctly classified. Overall, $87.8 \%$ of the males were correctly classified. A total of $3.9 \%$ of the females in the yes to both questions category, $46.8 \%$ of the yes to one of these questions, and $78.2 \%$ of the no to both of these questions were correctly classified. Overall, $55.5 \%$ of the females were correctly classified. 


\section{CHAPTER V \\ DISCUSSION}

The purpose of this preliminary study was to examine the specific domains of life satisfaction in relation to eating behaviors and weight perceptions among college males and females. As has been discussed previously, disordered eating behaviors affect one's health in a variety of ways, including, but not limited to, one's overall satisfaction with life. However, the results of the present study highlight the value of a domain-specific life satisfaction measure like the BMSLSS-C. For example, the domains of Satisfaction with Physical Appearance and Satisfaction with Self in descending order, were determined to be most strongly related to disordered eating behaviors/weight perception scores. These findings suggest it may be these domains which contribute the greatest proportion of variance to overall satisfaction with life in relation to disordered eating among college students observed in known literature (e.g., Esch \& Zullig, 2008; Greeno et al., 1998; Kitsantas et al., 2003; Valois et al., 2003; Watt et al., 2002; Zullig et al., 2007). Furthermore, all of the weight perception/dieting behavior variables were significantly associated with Physical Appearance except for the variable taking dietary supplements to lose bulk or weight for both men and women in the sample. The combined results suggest specific entry points for intervention from a quality of life perspective.

Although some domains of life satisfaction were found to be related with the majority of the eating behavior variables, others were not. Satisfaction with Romantic Relationships was significantly associated with the disordered eating/weight perception variable "worrying about weight issues" ( $\beta=.089, p=.043)$; however, it was not significant when genders were examined separately. Satisfaction with Friendships was correlated with binge eating behavior only $(\beta=$ $.134, p=.025)$ and Satisfaction with School was correlated only with how weight influences feelings about self $(\beta=-.159, p=.004)$. When genders were examined separately, among college females, Satisfaction with Family was correlated with taking dietary supplements to lose bulk or weight $(\beta=.117, p=.043)$ and Satisfaction with School was correlated with exercising to lose weight $(\beta=-.150, p=.023)$.

None of the domains of life satisfaction were related to vomiting or taking laxatives to lose weight nor taking dietary supplements to gain bulk or weight among both males and females. As hypothesized, the domains most strongly correlated with eating behaviors/weight perceptions among the college females and males in the study were Satisfaction with Physical 
Appearance and Satisfaction with Self in descending order. Disordered eating behaviors are correlated with drive for thinness in women and muscle gain for men. These results are consistent with previous research which suggests that women's perceptions of what is attractive to their same-sex peers was much thinner than the body shape and size that was actually picked by their peers as most ideal (Cohn \& Adler, 1992). Similarly, men's perceptions of what is attractive to their same-sex peers was much more muscular than the body size and shape that was actually picked by peers as most ideal (Cohn \& Adler, 1992). Thus, arguments can be made that college women and men who may be engaging in disordered eating behaviors are experiencing lower levels of satisfaction with their physical appearance because they are pursuing body images they perceive as most desirable among their peers yet may not themselves hold these body shapes as sizes as ideal. This is a common phenomena in the social norms literature regarding college alcohol use behavior, where students reliably overestimate the amount of alcohol their peers consume in relation to what they themselves report as consuming (Neighbors, Lewis, Fossos, \& Larimer, 2007; Turner, Perkins, \& Bauerle, 2008). This further supports the notion that college students' perceptions of social norms regarding the most desirable body image may not actually be what their peers view as ideal.

Previous research indicates that physical appearance is the greatest predictor of global self-esteem among both adolescent males and females (Harter, 1986). This may explain why Satisfaction with Physical Appearance was most strongly correlated with the disordered eating/poor weight perception variables. Previous research also indicates that one's self-esteem is based in part from evaluations of one's competencies or abilities (Harter, 1986; Rosenberg, 1979). Thus, it is plausible that college students in this study may be evaluating themselves against the body image which they believe is ideal and, because they are unable to achieve it, begin to engage in disordered eating practices. These practices may, in turn, lead to a decrease in satisfaction in physical appearance and self.

While self-esteem has been found to be related with life satisfaction, where higher levels of self-esteem are correlated with higher reported life satisfaction (Huebner \& Alderman, 1993), these two constructs are distinguishably different (Hubner, Gilman, \& Laughlin, 1999; Lucas, Diener, \& Suh, 1996). For example, self-esteem appears to be based more upon positive and negative affect (Diener \& Emmons, 1984), whereas life satisfaction is a cognitive judgment of one's life (Suh, Diener, Oishi, \& Triandis, 1998) and does not assess one's affect (Diener, 
Emmons, Larsen, \& Griffin, 1985) but rather, is more enduring. Positive affect demonstrates the extent to which one "feels enthusiastic, active, and alert" while negative affect demonstrates the extent to which one subjectively feels "distress and unpleasurable engagement" which can include the mood states such as "anger, contempt, disgust, guilt, fear, and nervousness" (p. 1063, Watson, Clark, \& Tellegen, 1988). Because self-esteem is influenced by one's affect, it is dependent on how one feels, making it a relatively unstable construct. In contrast, life satisfaction is relatively stable construct; it is a cognitive judgment of one's current in relation to a predetermined personal standard. Therefore, practitioners focusing on a client's physical appearance may experience greater success in treating unhealthy eating practices and behaviors, owing to its greater stability over time. However, interventions focusing on self-esteem should not be entirely abandoned. Instead, interventions incorporating both physical appearance and self-esteem may yield the greatest efficacy in decreasing unhealthy eating practices. Self-esteem should be not established upon superficial aspects such as one's appearance or conditional approval from friends or loved ones (Pyszczynski, Greenberg, \& Goldenberg, 2003). One's selfesteem is highly based on the perception of how others view them (Leary \& Baumeister, 2000). Thus, the maintenance of self-esteem within the physical appearance interventions would likely be most effective.

Because previous studies have indicated that females exhibit greater signs of disordered eating behaviors than do males (e.g., Kashubeck-West, Mintz, \& Weigold, 2005; Tata, Fox, \& Cooper, 2001; Thompson \& Sherman, 1999; Woodside et al., 2001), it is not surprising that females in this study reported higher levels of poor eating behaviors/weight perceptions than males. Previous research has also indicated that females reported less life satisfaction than males (e.g., Esch \& Zullig, 2008; Greeno et al., 1998; Valois et al., 2003; Zullig et al., 2007). Thus, it was not surprising that the females in the study reported lower levels of life satisfaction than did males. However, this was the first study to examine life satisfaction by domain in relation to disordered eating.

The domains of Physical Appearance and Self are highly correlated with one another $(0.70, p<.0001)$, but the tests of multicollinearity revealed that these two domains may measure distinct areas. Life satisfaction is thought to be moderated by the degree to which one's physical needs and psychological desires are satisfied (see Diener \& Seligman, 2004 for a review). Thus, a common first step to addressing addictive behaviors and disordered eating are attending to 
client ambivalence (Vitousek et al., 1998) toward their behavior. These results further demonstrate that one's physical appearance and satisfaction with self would be logical entry points to begin this process of addressing clients' disordered eating behaviors.

This strategy of attending to one's ambivalence may not be adequate enough for those with clinical eating disorders. For example, the most common reason for those who begin engaging in eating disorder practices is for control (e.g., Bryant-Waugh, Turner, East, \& Gamble, 2007; Katzman \& Lee, 1997; Meyer \& Russell, 1998) as a way to gain personal power. This need for control stems from the feeling that the individual is being discouraged to be independent, often times from parents. It appears that those who engage in disordered eating practices are mostly concerned with their outward appearances whereas those who have a clinical eating disorder are doing so in an effort to search for control over their lives. The results may indicate that the reasons for engaging in disordered eating behaviors and clinically diagnosed eating disorders are different which would have implications for practitioners. Unlike practitioners working with those who have clinical eating disorders, those who work with clients with disordered eating behaviors should focus bolstering satisfaction with physical appearance and self as a means to lessen and eventually halt the engagement in disordered eating practices. Consequently, future life satisfaction research should attempt to differentiate those with clinical eating disorders from those with sub-clinical eating disorders, as characteristics between the two may vary and it seems pertinent to explore this possible difference between reasons for occasionally engaging is disordered eating practices and having a clinical eating disorder.

Future research examining the differences between life satisfaction among those who engage in disordered eating versus those with a clinical eating disorder may prove to yield different results among the domains of life satisfaction. For example, those who engage in disordered eating practices may not experience as high rates of dissatisfaction among other domains such as Friends, Family, School whereas those with clinical eating disorders may report much higher rates of dissatisfaction, likely because one feels that these aspects of one's life are out of control and use the control of food in an effort to control one's life.

One way practitioners might be able to work with individuals with disordered eating is through probing them about why they believe they engage in such behaviors. Emerging literature suggests individuals with disordered eating symptoms may be very much amenable to working with and disclosing their symptoms in structured settings (Becker et al., 2004). Thus, it is 
plausible that in these structured settings, practitioners might probe into issues surrounding physical appearance and self to get to the root of the problem.

Because college students may be measuring themselves against an ideal standard which they believe is most desirable to their peers, but cannot achieve it, the standard by which they measure their physical appearance may be amenable to intervention through social marketing techniques. Social marketing is "designed to influence the voluntary behavior of target audiences to improve their personal welfare and that of the society of which they are a part" (p. 110, Andresen, 1994). Social marketing has been a technique used to gain change in a variety of settings and has been posited as a prevention technique for those with eating disorders (Thompson \& Heinberg, 1999). However, few studies actually applying this technique have been conducted within eating disorder or disordered eating populations. Within social marketing is social norming. Social norming can be utilized with those who engage in disordered eating practices through changing the concept of what the ideal body looks like. Future research testing this potential intervention strategy may allow for a paradigm shift in what the "ideal" body looks like and may lessen the number of persons who engage in disordered eating practices as a means by which to achieve the current "ideal" body.

\section{Limitations}

Although the findings of this preliminary study do provide helpful information in regards to which domains of life satisfaction are most correlated with eating behaviors/weight perceptions, limitations do exist. For example, approximately $92 \%$ of study participants in the current study were Caucasian and female. Therefore, the results should not be considered nationally representative. Some races/ethnicities may prove to be a protective factor in eating behaviors/weight perceptions, given that literature has indicated that Caucasians report more eating disturbances than non-Caucasians (Wildes, Emery, \& Simons, 2001). Therefore, future researchers should examine other races/ethnicities. Likewise, given that females are more afflicted with disordered eating behaviors than are males (e.g., Kashubeck-West, Mintz, \& Weigold, 2005; Tata, Fox, \& Cooper, 2001; Thompson \& Sherman, 1999; Woodside et al., 2001), if males were more represented, different results may have been found. However, because analyses were adjusted for gender, this fact should be cautiously interpreted. Additionally, the current study used cross-sectional data, which does not imply causality. Future research should examine this relationship longitudinally. Because the participants in the current 
study were traditional college students, it may be well to conduct a similar study with nontraditional college students such as non-residential and older college students. Lastly, because this preliminary study was unable to distinguish between different severities of abnormal eating behaviors (i.e., clinical, subclinical disordered eating, etc.) future research should identify and specify these differences for higher precision.

\section{Implications}

While there were some limitations of this study and suggestions for future research, this study did provide implications for practice. The current study determined the relationship between Physical Appearance and Self and eating behaviors/weight perception variables among males and females, where females are more affected by this relationship than are males. These findings suggest that intervention programs should first focus on participants' Satisfaction with Physical Appearance and Satisfaction with Self in an effort to reduce poor eating behaviors/weight perceptions and those interventions should be tailored differently for female and male college students. This tailoring could involve focus upon the areas which affect each respective gender (e.g., muscle gain in males and drive for thinness, self-esteem, and perfectionism in females).

Additionally, given that these two domains seem to be correlated with the greatest number of eating behaviors/weight perception variables, it would be well for practitioners to focus most on these two areas. Practitioners could focus on these two domains of Satisfaction with Physical Appearance and Satisfaction with Self through assessment of these and could delve deeper toward the root of the disordered eating behaviors using a structured setting. Furthermore, it would seem that because life satisfaction is a more enduring construct than selfesteem, practitioners should turn their attention toward Satisfaction with Physical Appearance and Satisfaction with Self in an effort to reduce poor eating behaviors while still incorporating aspects of self-esteem.

Lastly, practitioners conducting interventions could facilitate support groups for college students around campus who engage in unhealthy eating behaviors. High levels of life satisfaction are strongly associated with social support from family and friends (Dew \& Huebner, 1994; Gilman \& Huebner, 1997; Huebner, 1991). In addition, sub-clinical levels of life dissatisfaction have been shown to relate to social rejection among normal college students (Furr \& Funder, 1998). Taken together, these findings suggest that levels of social support may 
mediate the relationship between life dissatisfaction and poor weight perceptions and dieting behaviors. However, future research should test this hypothesis. Incorporating a support system for those students will also create a sense of accountability to not engage in these practices. 


\section{References}

Ackard, D. M., Croll, J. K., \& Kearney-Cooke, A. (2002). Dieting frequency among college females: Association with disordered eating, body image, and related psychological problems. Journal of Psychometric Research, 52, 129-136.

American College Health Association (2004). National College Health Assessment 2004 ACHANCHA 2004: User's Manual. Retrieved September 23, 2008, from: www.acha-ncha.org/ docs/ACHA-NCHA_USERS_MANUAL_ver2-004.pdf

American Psychiatric Association (2000). Diagnostic and statistical manual of mental disorders (Revised 4th ed.). Washington, DC.

Anderson, C. B., \& Bulik, C. M. (2004). Gender differences in compensatory behaviors, weight and shape salience, and drive for thinness. Eating Behaviors, 5, 1-11.

Andresen, A. R. (1994). Social marketing: Its definition and domain. Journal of Public Policy \& Marketing, 13, 108-114.

Attie, I., \& Brooks-Gunn, J. (1989). Development of eating problems in adolescent girls: A longitudinal study. Developmental Psychology, 25, 70-79.

Ball, K., \& Lee, C. (2000). Relationships between psychological stress, coping and disordered eating: A review. Psychology and Health, 14, 1007-1035.

Barker, E. T., \& Galambos, N. L. (2003). Body dissatisfaction of adolescent girls and boys: Risk and resource factors. Journal of Early Adolescence, 23 (2), 141-165.

Baron, R. M., \& Kenny, D. A. (1986). The moderator-mediator variable distinction in social psychological research: Conceptual, strategic, and statistical considerations. Journal of Personality and Social Psychology, 51(6), 1173-1182.

Battle, E. K., \& Brownell, K. D. (1996). Confronting a rising tide of eating disorders and obesity: Treatment vs. prevention and policy. Addictive Behaviors, 21(6), 755-765.

Becker, A. E., Franko, D. L., Nussbaum, K., \& Herzog, D. B. (2004). Secondary prevention for eating disorders: the impact of education, screening, and referral in a college-based screening program. International Journal of Eating Disorders, 36(2), 157-162.

Berkman, N. D., Lohr, K. N., \& Bulik, C. M. (2007). Outcomes of eating disorders: A systematic review of the literature. International Journal of Eating Disorders, 40, 293-309.

Bissell, K., \& Zhou, P. (2004). Must-see TV or ESPN: Entertainment and sports media exposure and body-image distortion in college women. Journal of Communication, 54, 1-5. 
Boyes, A. D., Fletcher, G. J. O., \& Latner, J. D. (2007). Male and female body image and dieting in the context of intimate relationships. Journal of Family Psychology, 21(4), 764-768.

Breen, H. B., Desilva, P., \& Espelage, D. L. (2005). Treatment of disordered eating. Current Medical Literature: Clinical Nutrition, 14(3), 40-45.

Brener, N. D., Collins, J. L., Kann, L., Warren, C. W., \& Williams, B. I. (1995). Reliability of the youth risk behavior survey questionnaire. American Journal of Epidemiology, 141(6), 575- 580.

Brouwers, M. (1988). Depressive though content among female college students with bulimia. Journal of Counseling \& Development, 66(9), 425-428.

Bryant-Waugh, R., Turner, H., East, P., \& Gamble, C. (2007). Developing a parenting skills-andsupport intervention for mothers with eating disorders and pre-school children part 1: Qualitative investigation of issues to include. European Eating Disorders Review, 15, 350-356.

Budd, G. (2007). Disordered eating: Young women's search for control and connection. Journal of Child and Adolescent Psychiatric Nursing, 20(2), 96-106.

Bunnell, D. W., Shenker, I. R., Nussbaum, M. P., Jacobson, M. S., \& Coolper, P. (1990). Subclinical versus formal eating disorders: Differentiating psychological features. International Journal of Eating Disorders, 9(3), 357-362.

Cahill, S., \& Mussap, A. J. (2007). Emotional reactions following exposure to idealized bodies predict unhealthy body change attitudes and behaviors in women and men. Journal of Psychosomatic Research, 62, 631-639.

Centers for Disease Control and Prevention (CDC). (1997). Division of Adolescent and School Health. National Center for Chronic Disease Prevention and Health Promotion: Youth risk behavior surveillance: National college health risk behavior survey-United States, 1995. MMWR Mortal Weekly Report, 46(SS-6), 1-56.

Christian, B., \& Mizes, J. S. (1997). Appraisal and coping deficits associated with eating disorders: Implications for treatment. Cognitive and Behavioral Practice, 4, 263-290.

Clinton, D. N., \& Glant, R. (1992). The eating disorders spectrum of DSM-II-R: Clinical features and psychosocial concomitants of 86 consecutive cases from a Swedish urban catchment area. Journal of Nervous and Mental Disease, 180, 244-250. 
Cockrum, J., \& White, P. (1985). Influences on the life satisfaction of never-married men and women. Family Relations, 34, 551-556.

Cohn, L. D., Adler, N. E. (1992). Female and male perceptions of ideal body shapes: Distorted views among Caucasian college students. Psychology of Women Quarterly, 16, 69-79.

Cohen, J. (1988). Statistical power analysis for the behavioral sciences. New York: Academic Press.

Cohen, D., \& Petrie, T. (2005). An examination of psychosocial correlates of disordered eating among undergraduate women. Sex Roles, 52, 29-44.

Conley, A., \& Boardman, J. D. (2007). Weight overestimation as an indicator of disordered eating behaviors among young women in the United States. International Journal of Eating Disorders, 40, 441-445.

Cook-Cottone, C., \& Phelps, L. (2003). Body dissatisfaction in college women: Identification of risk and protective factors to guide college counseling practices. Journal of College Counseling, 6, 80-89.

Cooley, E., \& Toray, T. (2001). Body image and personality predictors of eating disorder symptoms during the college years. International Journal of Eating Disorders, 30, 28-36.

Cummings, S. M. (2002). Predictors of psychological well-being among assisted-living residents. Health \& Social Work, 27(4), 293-302.

Cummins, R.A. (1996). The domains of life satisfaction: An attempt to order chaos. Social Indicators Research, 38, 303-332.

Davis, C., \& Cowles, M. (1989). A comparison of weight and diet concerns and personality factors among female athletes and non-athletes. Journal of Psychometric Research, 33, 527-536.

Demarest, J., \& Allen, R. (2000). Body image: Gender, ethnic, and age differences. The Journal of Social Psychology, 140(4), 465-472.

Deniz, M. E. (2006). The relationships among coping with stress, life satisfaction, decisionmaking styles and decision self-esteem: An investigation with Turkish university students. Social Behavior and Personality, 34(9), 1161-1170.

Dew, T. \& Huebner, E.S. (1994). Adolescents' perceived quality of life: An exploratory investigation. Journal of School Psychology, 32, 185-199. 
Diagnostic and Statistical Manual of mental disorders, $4^{\text {th }}$ ed.: DSM-IV-TR. Washington, D.S.: American Psychiatric Association, 2000.

Diener, E., \& Emmons, R. A. (1984). The independence of positive and negative affect. Journal of Personality and Social Psychology, 47(5), 1105-1117.

Diener, E., Emmons, R. A., Larsen, R. J., \& Griffin, S. (1985). The satisfaction with life scale. Journal of Personality Assessment, 49(1), 71-75.

Diener, E., \& Seligman, M. E. P. (2004). Beyond Money: Toward and Economy of well-being. Psychological Science in the Public Interest, 5, 1-31.

Engel, S. G., Johnson, C., Powers, P. S., Crosby, R. D., Wonderlich, S. A., Wittrock, D. A., Mitchell, J. E. (2003). Predictors of disordered eating in a sample of elite Division I college athletes. Eating Behaviors, 4, 333-343.

Esch, L. M., \& Zullig, K. J. (2008). Middle school students' weight perceptions, dieting behaviors and life satisfaction. American Journal of Health Education, 39(6), 345-352.

Flece, D., \& Perry, J. (1995). Quality of life: Its definition and measurement. Research in Developmental Disabilities, 16(1), 51-74.

Fredrickson, B. L., \& Roberts, T. (1997). Objectification theory: Toward understanding women's lived experiences and mental health risks. Psychology of Women Quarterly, 21(2), 173206.

Furnham, A., Calnan, A. (1998). Eating disturbance, self-esteem, reasons for exercising and body weight dissatisfaction in adolescent males. European Eating Disorders Review, $6(1), 58-72$.

Furr, R. M., \& Funder, D. (1998). A multimodal analysis of personal negativity. Journal of Personality and Social Psychology, 74, 1580-1591.

Garfinkel, P. E., Goldbloom, D., Davis, R., Olmsted, M. P., Garner, D. M., \& Halmi, K. A. (1992). Body dissatisfaction in bulimia nervosa: Relationship to weight and shape concerns and psychological functioning. International Journal of Eating Disorders, 11, 151-161.

Garner, D. M., Olmstead, M. P., \& Polivy, J. Development and validation of a multidimensional eating disorder inventory for anorexia nervosa and bulimia. International Journal of Eating Disorders, 2, 15-34.

Ghaderi, A., \& Scott, B. (2001). Prevalence, incidence and prospective risk factors for eating 
disorders. Acta Psychiatrica Scandinavica, 104, 122-130.

Giles, S. M., Helme, D., \& Kraemar, M. (2007). Predicting disordered eating intentions among incoming college freshman: An analysis of social norms and body esteem. Communication Studies, 58(4), 395-410.

Gilman, R., \& Huebner, E.S. (1997). Children's reports of their life satisfaction: Convergence across raters, time and response formats. School Psychology International, 18, 133-147.

Gilman, R., Huebner, E. S., \& Laughlin, J. E. (2000). A first study of the Multidimensional Students’ Life Satisfaction Scale with adolescents. Social Indicators Research, 52(3), 135-160.

Gleaves, D. H., Williamson, D. A., Eberenz, K. P., Sebastian, S. B., \& Barker, S. E. (1995). Clarifying body-image disturbance: Analysis of a multidimensional model using structural modeling. Journal of Personality Assessment, 64, 478-493.

Goldschmidt, A. B., Tanofsky-Kraff, M., Goossens, L., Eddy, K. T., Ringham, R., Yanovski, S. Z., et al. (2008). Subtyping children and adolescents with loss of control eating by negative affect and dietary restraint. Behavior Research \& Therapy, 46(7), 777-787.

Gravener, J. A., Haedt, A. A., Heatherton, T. F., \& Keel, P. K. (2008). Gender and age differences in associations between peer dieting and drive for thinness. International Journal of Eating Disorders, 41, 57-63.

Gray, D., \& Calsyn, R. J. (1989). The relationship of stress and social support to life satisfaction: Age effects. Journal of Community Psychology, 17, 214-221.

Greeno, C.G., Jackson, C., Williams, E. L., \& Fortmann, S. P. (1998). The effect of perceived control over eating on the life satisfaction of women and men: Results from a community sample. International Journal of Eating Disorders, 24(4), 415-419.

Grieve, F., Wann, D., Henson, C., \& Ford, P. (2006). Healthy and unhealthy weight management practices in collegiate men and women. Journal of Sport Behavior, 29, 229-239.

Halvorsen, I., \& Heyerdahl, S. (2006). Girls with anorexia nervosa as young adults: Personality, self-esteem, and life satisfaction. International Journal of Eating Disorders, 39, 285-293.

Harrison, K., \& Cantor, J. (1997). The relationship between media consumption and eating disorders. Journal of Communication, 47(1), 40-67. 
Harter, S. (1986). Processes underlying the construction, maintenance, and enhancement of the self-concept in children. In J. Suls \& A. W. Greenwald (Eds.), Psychological perspectives on the self(Vol. 3, pp. 136-182). Hillsdale, NJ: Erlbaum.

Hautala, L., Junnila, J., Helenius, H., Vaananen, A., Liuksila, P., Raiha, H. et al. (2008). Adolescents with fluctuating symptoms of eating disorders: A 1-year prospective study. Journal of Advanced Nursing, 62(6), 674-680.

Heatherton, T. F., Mahamedi, F., Striepe, M., Field, A. E., \& Kell, P. (1997). A 10-year longitudinal study of body weight, dieting, and eating disorder symptoms. Journal of Abnormal Psychology, 106(1), 117-125.

Hewitt, P., \& Flett, G. (1991). Perfectionism in the self and social contexts: Conceptualization, assessment, and association with psychopathology. Journal of Personality and Social Psychology, 60, 456-470.

Heywood, S., \& McCabe, M. P. (2006). Negative affect as a mediator between body dissatisfaction and extreme weight loss and muscle gain behaviors. Journal of Health Psychology, 11(6), 833-844.

Hill, A. J., Oliver, S., \& Rogers, P. J. (1992). Eating in the adult world: The rise of dieting in childhood and related indicators. British Journal of Clinical Psychology, 31, 95-105.

Huebner, E. S. (1994). Preliminary development and validation of a multidimensional life scale for children. Psychological Assessment, 6, 149-158.

Huebner, E.S. (1991). Correlates of life satisfaction in children. School Psychology Quarterly, 6, 103-111.

Huebner, E. S., \& Alderman, G. L. (1993). Convergent and discriminant validation of a children's life satisfaction scale: Its relationship to self- and teacher-reported psychological problems and school functioning. Social Indicators Research, 30, 71-82.

Huebner, E. S., Gilman, R., \& Laughlin, J. E. (1999). A multimethod investigation of the multidimensionality of children's well-being reports: Discriminant validity of life satisfaction and self-esteem. Social Indicators Research, 46, 1-22.

Hughes, M. E., Waite, L. J., Hawkley, L. C., \& Cacioppo, J. T. (2004). A short scale for measuring loneliness in large surveys. Research on Aging, 26(6), 655-672. 
Humphreys, J. D., Clopton, J.R., \& Reich, D. A. (2007). Disordered eating behavior and obsessive compulsive symptoms in college students: Cognitive and affective similarities. Eating Disorders, 15, 247-259.

Hun, S. K., \& Hyun, S. K. (2008). Risk factors for suicide attempts among Korean adolescents. Child Psychiatry \& Human Development, 39(3), 221-235.

Jackson, T., Weiss, K. E., Lunquist, J. J., \& Soderlind, A. (2005). Sociotropy and perceptions of interpersonal relationships as predictors of eating disturbances among college women: Two prospective studies. The Journal of Genetic Psychology, 166(3), 346-359.

Jacobson, R., \& Robins, C. J. (1989). Social dependency and social support in bulimic and nonbulimic women. International Journal of Eating Disorders, 8(6), 665-670.

Jaffe, A. C., \& Singer, L. T. (1989). Atypical eating disorders in young children. International Journal of Eating Disorders, 8, 575-582.

Jenkins, S. K., Rew, L., \& Sternglanz, R. W. (2005). Eating behaviors among school-age children associated with perceptions of stress. Issues in Comprehensive Pediatric Nursing, 28(3), 175-191.

Johnson, C., Crosby, R., Engel, S., Mitchell, J., Powers, P., Wittrock, D., \& Wonderlich, S. (2004). Gender, ethnicity, self-esteem and disordered eating among college athletes. Eating Behaviors, 5, 147-156.

Kashubeck-West, S., Mintz, L. B., \& Weigold, I. (2005). Separating the effects of gender and weight-loss desire on body satisfaction and disordered eating behavior. Sex Roles, 53(7), 505-520.

Katzman, M. A., \& Lee, S. (1997). Beyond body image: The integration of feminist and transcultural theories in the understanding of self starvation. International Journal of Eating Disorders, 22, 385-394.

Keel, P. K., Fulkerson, J. A., \& Leon, G. R. (1997). Disordered eating precursors in pre- and early adolescent girls and boys. Journal of Youth and Adolescence, 26, 203-216.

Kitsanatas, A., Gilligan, T. D., \& Kamata, A. (2003). College women with eating disorders: Selfregulation, life satisfaction, and positive/negative affect. The Journal of Psychology, $137(4), 381-395$. 
Klemchuk, H. P., Hutchinson, C. B., \& Frank, R. I. (1990). Body dissatisfaction and eating-related problems on the college campus: Usefulness of the Eating Disorder Inventory with a nonclinical population. Journal of Counseling Psychology, 37(3), 297305.

Laliberte, M., Newton, M., McCabe, R., Mills, J. S. (2007). Controlling your weight versus controlling your lifestyle: How beliefs about weight control affect risk for disordered eating, body dissatisfaction and self-esteem. Cognitive Therapy Research, 31, 853-869.

Leary, M. R., \& Baumeister, R. F. (2000). The nature and function of self-esteem: Sociometer theory. In M. Zanna (Ed.), Advances in experimental social psychology (Vol. 32, pp. 162). San Diego, CA: Academic Press.

Levitt, D. H. (2003). Drive for thinness and fear of fat: Separate yet related constructs? Eating Disorders: The Journal of Treatment and Prevention, 11, 237-250.

Lock, J., Reisel, B., \& Steiner, H. (2001). Associated health risks of adolescents with disordered eating: How different are they from their peers? Results from a high school survey. Child Psychiatry and Human Development, 31(3), 249-265.

Lucas, R. E., Diener, E., \& Suh, E. (1996). Discriminant validity of well-being measures. Journal of Personality and Social Psychology, 71(3), 616-628.

Macedo, A., Soares, M. J., Azevedo, M. H., Gomes, A., Pereira, A. T., Maia, B., \& Pato, M. (2007). Perfectionism and eating attitudes in Portuguese university students. European Eating Disorders Review, 15, 296-304.

Measelle, J. R., Stice, E., Hogansen, J. M. (2006). Developmental trajectories of co-occurring depressive, eating, antisocial, and substance abuse problems in female adolescents. Journal of Abnormal Psychology, 115(3), 524-538.

Miami University (2006). Fact book 2006-2007. Retrieved April 19, 2009 from, http://www. units.muohio.edu/oir/FactBook/FB200607/FB0607Main.htm

Mitz, L. B., \& Betz, N. E. (1988). Prevalence and correlates of eating disordered behaviors among undergraduate women. Journal of Counseling Psychology, 35, 463-471.

Mintz, L. B., \& Betz, N. E. (1986). Sex differences in the nature, realism, and correlates of body image. Sex Roles, 15(3), 185-196.

Moore, D. (2007). Self perceptions and social misconceptions: The implications of gender traits locus of control and life satisfaction. Sex Roles, 56, 767-780. 
Muscle dissatisfaction in young men. (2004). Eating Disorders Reviews, 15(4), 7-7.

Meyer, D. F., \& Russell, R. K. (1998). Caretaking, separation from parents, and the development of eating disorders. Journal of Counseling and Development, 76(2), 166-173.

Neighbors, C. L., Lewis, M., Fossos, N., \& Larimer, M. E. (2007). Are social norms the best predictors of outcomes among heavy-drinking college students? Journal of Studies on Alcohol and Drugs, 68, 556-565.

O'Dea, J.A., \& Abraham, S. (1999). Onset of disordered eating attitudes and behaviors in early adolescence: Interplay of pubertal status, gender, weight and age. Adolescence, 34, 671679.

Palmore, E., \& Luikart, C. (1972). Health and social factors related to life satisfaction. Journal of Health \& Social Behavior, 13, 68-80.

Pasman, L., \& Thompson, J. K. (1988). Body image and eating disturbance in obligatory runners, obligatory weightlifters, and sedentary individuals. International Journal of Eating Disorders, 7(6), 759-769.

Polivy, J., \& Herman, C. P. (2002). Causes of eating disorders. Annual Review of Psychology, $53,187-213$.

Polivy, J., \& Herman, C. P. (1987). Diagnosis and treatment of normal eating. Journal of Consulting and Clinical Psychology, 55(5), 635-644.

Post, M. W. M., Van Dijk, A. J., Van Asbeck, F. W. A., \& Schrijvers, A. J. P. (1998). Life satisfaction of persons with spinal cord injury compared to a population group. Scandinavian Journal of Rehabilitation Medicine, 30(1), 23-30.

Prouty, A. M., Protinsky, H. O., \& Canady, D. (2002). College women: Eating behaviors and help-seeking preferences. Adolescence, 37(146), 353-363.

Pyszczynski, T., Greenberg, J., \& Goldenberg, J. (2003). Freedom in the balance: On the defense, growth, and expansion of the self. In M. Leary \& J. Tangney (Eds.), Handbook of self and identity (pp. 314-343). New York: Guilford Press.

Quimby, J. L., \& O’Brien, K. M. (2006). Predictors of well-being among nontraditional female students with children. Journal of Counseling \& Development, 84, 451-460. 
Reinking, M., \& Alexander, L. (2005). Prevalence of disordered-eating behaviors in undergraduate female collegiate athletes and nonathletes. Journal of Athletic Training, 40, 47-52.

Ricciardeli, L. A., \& McCabe, M. P. (2004). A biopsychosocial model of disordered eating and the pursuit of muscularity in adolescent boys. Psychological Bulletin, 130,179-205.

Rorty, M., Yager, J., Buckwalter, J. G., \& Rossotto, E. (1999). Social support, social adjustment, and recovery status in bulimia nervosa. Journal of Eating Disorders, 26, 1-12.

Rosenberg, M. (1979). Conceiving the self. New York: Basic Books.

Rosenthal, K. R., Gesten, E. L., \& Shiffman, S. (1986), Gender and sex role differences in the perception of social support. Sex Roles, 14, 481-499.

Rosenzweig, M., \& Spruill, J. (1987). Twenty years after twiggy: A retrospective investigation of bulimic-like behaviors. International Journal of Eating Disorder, 6(1), 59-65.

Sands, R. (2000). Reconceptualization of body image and drive for thinness. International Journal of Eating Disorders, 28, 397-407.

Santonastaso, P., Friederici, S., \& Favaro, A. (1999). Full and partial syndromes in eating disorders: A 1-year prospective study of risk factors among female students. Psychopathology, 32, 50-56.

Santos, M., Richards, C. S., \& Bleckley, M. K. (2007). Comorbidity between depression and disordered eating in adolescents. Eating Behaviors, 8, 440-449.

Schellenberg, G. (2004). Perceptions of Canadians: A sense of belonging, confident and trust. Canadian Social Trends, 75, 16-21.

Shea, M., \& Pritchard, M. E. (2007). Is self-esteem the primary predictor of disordered eating? Personality and Individual Differences, 42, 1527-1537.

Shisslak, C. M., Crago, M., \& Estes, L. S. (1995). The spectrum of eating disturbances. International Journal of Eating Disorders, 18(3), 209-219.

Shisslak, C. M., Crago, M., \& Yates, A. (1989). Typical patterns in atypical anorexia nervosa. Psychosomatics, 30, 307-311.

Shomaker, L. S., \& Furman, W. (2007). Same-sex peers' influence on young women's body image: An experimental manipulation. Journal of Social \& Clinical Psychology, 26(8), 871-895. 
Shutz, H. K., \& Paxton, S. J. (2007). Friendship quality, body dissatisfaction, dieting and disordered eating in adolescent girls. British Journal of Clinical Psychology, 46, 67-83.

Siebert, D. C., Mutran, E. J., \& Reitzes, D. C. (1999). Friendship and social support: The importance of role identity to aging adults. Social Work, 44(6), 522-533.

Skomorovsky, A., Matheson, K., \& Anisman, H. (2006). The buffering role of social support perceptions in relation to eating disturbances among women in abusive dating relationships. Sex Roles, 54, 627-638.

Sohlber, S. S., Norring, C. E. A., Rosmark, B. E. (1992). Prediction of the course of anorexia nervosa/bulimia nervosa over three years. International Journal of Eating Disorders, 12(2), 121-131.

Steiner, H., \& Lock, J. (1998). Anorexia Nervosa in children and adolescents: A review of the past 10 years. Journal of the American Academy of Child and Adolescent Psychiatry, 37, 352-359, 1998.

Stice, E., Killen, J. D., Hayward, C., \& Taylor, C. B. (1998). Age of onset for binge eating and purging during late adolescence: A 4-year survival analysis. Journal of Abnormal Psychology, 107(4), 671-675.

Striegel-Moore, R. H., Dohm, F., Kraemer, H. C., Schreiber, G. B., Taylor, C. B., \& Daniels, S. R. (2007). Risk factors for binge-eating disorders: An exploratory study. International Journal of Eating Disorders, 40, 481-487.

Striegel-Moore, R., Siberstein, L. R., Frensch, P., \& Rodin, J. (1989). A prospective study of disordered eating among college students. International Journal of Eating Disorders, 8 , 499-509.

Suh, E., Diener, E., Oishi, S., \& Triandis, H. C. (1998). The shifting basis of life satisfaction judgments across cultures: Emotions versus norms. Journal of Personality and Social Psychology, 74(2), 482-493.

Suldo, S. M., \& Huebner, E. S. (2006). Is extremely high life satisfaction during adolescence advantageous? Social Indicators Research, 78, 179-203.

Swallen, K. C., Reither, E. N., Haas, S. A., \& Meier, A. M. (2005). Overweight, obesity, and health-related quality of life among adolescents: The national longitudinal study of adolescent health. Pediatrics, 115(2), 340-347. 
Swami, V., Chamorro-Premuzic, T., Sinniah, D., Maniam, T., Kannan, K., Stanistreet, D., \& Furnham, A. (2007). General health mediates the relationship between loneliness, life satisfaction and depression. Social Psychiatry \& Psychiatric Epidemiology, 42, 161-166.

Sypeck, M. F., Gray, J. J., \& Ahrens, A. H. (2004). No longer just a pretty face: Fashion magazines' depictions of ideal female beauty from 1959 to 1999. International Journal of Eating Disorders, 36, 342-247.

Tata, P., Fox, J., \& Cooper, J. (2001). An investigation into the influence of gender and parenting styles on excessive exercise and disordered eating. European Eating Disorders Review, 9, 194-206.

Thome, J., \& Espelage, D. L. (2004). Relations among exercise, coping, disordered eating, and psychological health among college students. Eating Behaviors, 5, 337-351.

Thompson, J. K., \& Heinberg, L. J. (1999). The media's influence on body image disturbance and eating disorders: We're reviled them, now can we rehabilitate them? Journal of Social Issues, 55(2), 339-353.

Tiller, J. M., Sloane, G., Schmidt, U., Troop, N., Power, M., \& Treasure, J. L. (1997). Social support in patients with anorexia nervosa and bulimia nervosa. International Journal of Eating Disorders, 21(1), 31-38.

Turner, J., Perkins, H. W., \& Bauerle, J. (2008). Declining negative consequences related to alcohol misuse among students exposed to a social norms marketing intervention on a college campus. Journal of American College Health, 57(1), 85-93.

Tylka, T., \& Hill, M. (2004). Objectification theory as it relates to disordered eating among college women. Sex Roles, 51, 719-632.

Tylka, T. L., \& Subich, L. M. (1999). Exploring the construct validity of the eating disorder continuum. Journal of Counseling Psychology, 46, 268-276.

Valios, R. F., Zullig, J. K., Huebner, E. S., \& Drane, J. W. (2003). Dieting behaviors, weight perceptions, and life satisfaction among public high school adolescents. Eating Disorders, 11 (4), 271-288.

Valios, R. F., Zullig, J. K., Huebner, E. S., \& Drane, J. W. (2004). Life satisfaction and suicide among high school adolescents. Social Indicators Research, 66, 81.

Vaughan, K. K., \& Fouts, G. T. (2003). Changes in television and magazine exposure and eating disorder symptomology. Sex Roles, 49(7/8), 313-320. 
Vervaet, M., van Heeringen, C., \& Audenaert, K. (2004). Is drive for thinness in anorectic patients associated with personality characteristics. European Eating Disorders Interview, 12, 375-379.

Vieno, A., Santinello, M., Pastore, M., \& Perkins, D.D. (2007). Social support, sense of community in school, and self-efficacy as resources during early adolescence: An integrative model. American Journal of Community Psychology, 39, 177-190.

Vitousek, K., Watson, S., \& Wilson, G. (1998). Enhancing motivation for change in treatmentresistant eating disorders. Clinical Psychology Review, 18(4), 391-420.

Vohs, K. D., Bardone, A. M., Joiner, T.E., Jr., Abramson, L. Y., \& Heatherton, T. F. (1999). Perfectionism, perceived weight status, and self-esteem interact to predict bulimic symptoms: A model of bulimic symptom development. Journal of Abnormal Psychology, 4, 695-700.

Vohs, K. D., Heatherton, T. F., \& Herrin, M. (2001). Disordered eating and the transition to college: A prospective study. International Journal of Eating Disorders, 29, 280-288.

Wan, C. K., Jaccard, J., \& Ramey, S. L. (1996). The relationship between social support and life satisfaction as a function of family structure. Journal of Marriage and the Family, 58, 502-513.

Watson, D., Clark, L. A., \& Tellegen, A. (1988). Development and validation of brief measures of positive and negative affect: The PANAS scales. Journal of Personality and Social Psychology, 54(6), 1063-1070.

Watt, T. T., Sharp, S. F., \& Atkins, L. (2002). Personal control and disordered eating patterns among college females. Journal of Applied Social Psychology, 32(12), 2502-2512.

Wharton, C. M., Adams, T., \& Hampl, J. S. (2008). Weight loss practices and body weight perceptions among US college students. Journal of American College Health, 56 (5), 579-584.

Wildes, J. E., Emery, R. E., \& Simons, A. D. (2001). The role of ethnicity and culture in the development of eating disturbance and body dissatisfaction: A meta-analytic review. Clinical Psychology Review, 21(4), 521-551.

Windle, G., \& Woods, R. T. (2004) Variations in subjective wellbeing: The mediating role of a psychological resource. Ageing \& Society, 24, 583-602. 
Wolff, G. E., Crosby, R. D., Roberts, J. A., \& Wittrock, D. A. (2000). Differences in daily stress, mood, coping, and eating behavior in binge eating and nonbinge eating college women. Addictive Behaviors, 25(2), 205-216.

Woodside, D., Garfinkel, P., Lin, E., Goering, P., Kaplan, A., Goldbloom, D., et al. (2001). Comparisons of men with full or partial eating disorders, men without eating disorders, and women with eating disorders in the community. The American Journal of Psychiatry, $158,570-575$.

Yelland, C., \& Tiggemann, M. (2003). Muscularity and the gay ideal: Body dissatisfaction and disordered eating in homosexual men. Eating Behaviors, 4, 107-166.

Zullig, K. J., Huebner, E. S., Patton, J. M., \& Murray, K. A. (in press). The Brief Multidimensional Students' Life Satisfaction Scale-College version. American Journal of Health Behavior.

Zullig, K. J., Pun, S. M., \& Huebner, E. S. (2007). Life satisfaction, dieting behavior, and weight perceptions among college students. Applied Research in Quality of Life, 2, 17-31.

Zullig, K. J., Valios, R. F., Huebner, E. S., \& Drane, J. W. (2005). Adolescent health-related quality of life and perceived satisfaction with life. Quality of Life Research, 14, 1573 1584.

Zullig, K. J., Valios, R. F., Huebner, E. S., \& Drane, J. W. (2001). Relationship between perceived life satisfaction and adolescents' substance abuse. Journal of Adolescent Health, 29, 279-288. 